\title{
ENTERPRISE RISK MANAGEMENT, INSURER VALUE MAXIMISATION, AND MARKET FRICTIONS*
}

\author{
BY
}

SHaun Yow AND Michael SHERRIS

\begin{abstract}
Enterprise risk management has become a major focus for insurers and reinsurers. Capitalization and pricing decisions are recognized as critical to firm value maximization. Market imperfections including frictional costs of capital such as taxes, agency costs, and financial distress costs are an important motivation for enterprise risk management. Risk management reduces the volatility of financial performance and can have a significant impact on firm value maximization by reducing the impact of frictional costs. Insurers operate in imperfect markets where demand elasticity of policyholders and preferences for financial quality of insurers are important determinants of capitalization and pricing strategies. In this paper, we analyze the optimization of enterprise or firm value in a model with market imperfections. A realistic model of an insurer is developed and calibrated.

Frictional costs, imperfectly competitive demand elasticity, and preferences for financial quality are explicitly modelled and implications for enterprise risk management are quantified.
\end{abstract}

\section{INTRODUCTION}

Risk management for an insurer has generally focussed on determining the level of capitalization using risk based or economic capital. Using economic capital measures for financial decision making is becoming a standard for financial service firms including insurers. A 2005 survey by PricewaterhouseCoopers of 200 senior executives in financial service firms throughout Asia, Europe, and the U.S., with 7\% of respondents from the insurance industry, found that $44 \%$ quantified risk with economic capital and $13 \%$ planned to use economic capital within 12 months. The survey revealed that economic

* Acknowledgement: The authors acknowledge financial support from Australian Research Council Discovery Grants DP0663090 and DP0556775 and support from the UNSW Actuarial Foundation of the Institute of Actuaries of Australia. Support from Georgia State University 2007 Bowles Symposium and the ERM Symposium is gratefully acknowledged. Yow acknowledges the financial support of Ernst and Young and the award of the Faculty of Business Honours Year Scholarship. 
capital is a critical component for the success of a financial service firm. As a strategic tool, economic capital impacted pricing policies in $20 \%$ of firms and $10 \%$ of respondents discontinued unprofitable lines of business based on economic capital. The paper by Hitchcox et al. [15] discusses the cost of capital and the impact of frictional costs for a model insurer with an objective of assessing target capital and premium loadings for insurers. Swiss Re [31] also assess the cost of capital for insurers and analyze frictional costs, referred to as the insurance cost of capital.

In practice enterprise value maximization has a broader focus than economic capital and must consider the impact of liability pricing, capitalization, and asset-liability management decisions on capital costs, risk, and firm value. The famous Modigliani-Miller theorem (Modigliani and Miller [22]) states that in perfect markets a firm's capital structure, which is an integral component of its risk management, is irrelevant to firm value. Risk management will not impact firm value in perfect markets. In practice capital market imperfections and informational asymmetries create frictional costs for the firm. These frictional costs provide the economic rationale for risk management and, as demonstrated in this paper, have a significant impact on a firm's optimal capital structure and pricing strategies.

The economic motivation for risk management is to maximize firm value. Part I of Culp [3], the Chapter by Hommel "Value Based Motives for Risk Management" in Frenkel, Hommel, and Rudolf [10] as well as Chapter 3 of Stulz [29] provide excellent coverage of how risk management can be used to increase firm value. McNeil et al. [20] also discuss three ways in which enterprise risk management enhances insurer value by minimizing frictional costs. First, risk management reduces cash flow volatility and since firm profits allowing for taxes are convex, risk management increases expected after-tax profits. Second, reduced cash flow volatility also reduces the costs of financial distress by lowering the probability of insolvency and the expected costs of financial distress. Finally, since external financing is more costly than internal financing, reduced cash flow volatility will reduce the expected requirement for, and expected costs of, external financing. Agency costs are also an important frictional cost for an insurer. The management of an insurer are agents of the shareholders, making investment, underwriting, and risk management decisions to maximize shareholder value. Management will act in self interest and are costly to monitor. Insurers are complex and agency costs of capital, such as sub-optimal risk management decisions and management perquisites, reduce firm value and are an important risk management issue.

Capital also impacts an insurer's pricing strategy and the pricing strategy is an important source of risk and value. As Merton and Perold [21] note, for an insurer debtholders are also its primary customers. An insurer's underwriting risk is not easily traded or hedged and insurers hold capital to ensure policyholder claims are met. Policyholders are concerned about financial quality and the payment of claims. Empirical evidence in Phillips, Cummins, and Allen [25] shows that the demand for insurance is influenced by the financial 
quality of the insurer. Insurers operate in a regulated environment where risk based capital is held to ensure a low risk of insolvency or financial distress. For banks and insurers, economic capital is central to enterprise risk management but understanding the interaction between capital and pricing is critical to the successful financial operation of an insurer.

Panning [24] develops a firm value maximizing model for an insurer based on value added which is defined as the present value of future after-tax profits allowing for insurer default in excess of surplus. Zanjani [36] formally develops a firm value maximizing model where capital is costly to hold because of frictional costs and policyholders have inelastic demand and care about the financial quality of the insurer. Zanjani [36] provides analytical results for insurer capitalization and pricing with examples based on a normal distribution of risks. In his conclusion on page 30, Zanjani [36] states:

Understanding the exact nature of capital costs and calibrating their influence on market behavior are important areas for future research.

In this paper we examine the impact of frictional costs and market imperfections on enterprise risk management, capitalization, and pricing decisions in a multi-line insurer. Our aim is to demonstrate the importance of the different market frictions and provide guidance on enterprise risk management strategies, optimal capitalization, and multi-line insurance pricing. Optimal strategies are determined by maximizing insurer enterprise value added (EVA) using a value based measure allowing for frictional costs of capital that is different to economic value added, the financial performance measure developed by Stern Stewart and Co., and similar to that of Panning [24]. The model assumptions are based on those of Zanjani [36] and we include frictional costs, imperfect demand, and then optimize EVA through capitalization and pricing strategies. We model price elasticity across different lines of business. We study in detail the impact of market frictions for taxes, agency costs, and financial distress costs using a calibrated model of an insurer representative of the Australian general insurance industry.

We find that the impact of frictional costs on an insurer's optimal risk based capital is more significant than would at first be expected and this varies significantly by the type of frictional cost. Higher tax and agency costs of capital result in reductions in optimal levels of capitalization and higher firmwide insolvency risk since costs of capital reduce the returns to shareholders. Conversely, higher costs of financial distress create an incentive for insurers to increase the capitalization of the firm and improve financial quality in order to write business at value-adding prices. We also find that under optimal strategies shareholders bear most of the frictional costs of capital and that these are not in general passed on to policyholders through higher insurance prices.

Enterprise risk management has an objective of enhancing the value of an insurer through its risk management strategies. This paper demonstrates that because of the importance of financial quality to pricing and the impact of 
imperfect demand elasticity, risk based capital is a critical component of the optimal strategy for an enterprise maximizing insurer. Understanding the link between enterprise value, frictional costs, capital, and pricing strategies is also fundamental to successful financial performance and optimal risk management for an insurer.

The remainder of this paper is organized as follows. Section 2 develops a single-period economic model of an insurer in imperfect markets. Section 3 calibrates the model to Australian general insurance industry data and models policyholder demand for insurance. Section 4 presents results and a discussion of findings. Section 5 concludes.

\section{THE INSURER MOdeL}

Doherty and Garven [9] develop a single-period option pricing framework for insurer pricing and capitalization including default risk and taxation. We develop a framework for analyzing the optimal pricing and capitalization of an insurer in imperfect markets based on Zanjani [36]. The objective we use for firm value maximization is similar to that of Panning [24]. The model is a single-period model of an insurer that writes $N$ lines of business at time 0 , with claims due to be paid at time 1 . While we focus on the single-period model, the model can be extended to a multi-period model by assuming business is renewed at the end of each year and optimal capital and pricing decisions are made in the light of evolving experience. Although Panning [24] assumes multi-period insurer cash flows, the optimization is at a single initial point of time and does not involve dynamic decision making.

Three types of frictional costs are included: taxes, agency costs of capital, and costs of financial distress. Importantly, insurance product markets are not assumed to be perfectly competitive as is often assumed for financial asset markets. In practice, information asymmetries and switching costs for policyholders result in a downward sloping demand curve as a function of price per unit of risk. We model the price elasticity of demand by line. Policyholders are also assumed to care about enterprise wide insolvency risk, so that insurers with higher capitalization and financial quality have higher market premiums. The insurer determines capital and pricing strategies that maximize EVA allowing for costs of capital and imperfect demand elasticity for its policies. The result is an optimal supply of insurance policies based on value maximization in the presence of frictional costs allowing for demand by policyholders for each line of business. Optimal capital and pricing strategies are determined in the model.

Value maximization as a firm objective is consistent with modern corporate financial theory and the economic foundation of risk management. In perfect markets, the Fisher Separation Theorem (MacMinn [18]) implies that investors with diverse risk preferences will invest capital into firms and delegate production decisions to management, whose objective is to maximize firm value 
regardless of investor risk preferences. Smith [28] demonstrates that Fisher Separation also holds in the case of incomplete markets when investor preferences, as given by their utility, satisfy conditions of additivity and constant relative risk aversion. Without frictions, value maximizing firms should act as if they were risk neutral. Frictional costs create convexity in the after-tax profits of the firm. Frictional costs are the costs of holding capital in the firm and are regarded as the insurance costs of capital (Swiss Re [31]). They impact financial decision making by creating incentives to reduce risk and volatility in order to maximize firm value. Explicitly modelling frictional costs allows the quantification of the costs and benefits of holding too much capital as well as the costs and benefits of holding too little capital.

The main contributor to value added in an insurer is the profit margin by line of business. Determining optimal pricing strategies that maximize profit margins by line, taking into account frictional costs and imperfect policyholder demand, has important implications for optimal capitalization and hence for enterprise risk management. The optimization approach does not require the allocation of capital or frictional costs of capital to line of business for pricing since optimal prices are determined directly taking into account policyholder demand and preferences for financial quality.

The model is a single-period model where the insurer determines an optimal capital and pricing strategy that will maximize EVA. EVA is the increase in value of the insurer equity from writing the insurance business over and above the initial capital subscribed allowing for frictional costs of capital. The model is calibrated to representative insurer data and implications for enterprise risk management are assessed. The model includes market imperfections and allows for capital and pricing strategy interactions. The model explicitly allows for optimal insurer supply, based on its value maximization, and policyholder demand is determined from the by-line price elasticities. The model is solved numerically because of the interdependencies in the balance sheet and the optimization determines the risk based capital and value maximizing profit loadings by line.

\subsection{Insurer Balance Sheet and Model Assumptions}

D'Arcy and Gorvett [8] develop a hypothetical but representative insurer in order to examine the impact of varying assumptions on underwriting profit margins. We take a similar approach to construct a representative insurer, however, our objective is to determine optimal capitalization and insurer profit margins allowing for varying frictional costs and, importantly, including policyholder demand elasticity and a preference for financial quality in the model. We follow Doherty and Garven [9] and Sherris [26] in the construction of the balance sheet, ignoring frictional costs. We then develop a market value based balance sheet incorporating frictional costs of capital. The balance sheet of the insurer is determined using economic valuation of cashflows. 
Initial cash capital subscribed at time 0 is denoted by $R_{0}$. Premium revenue at time 0 for sales from the $N$ lines of business is

$$
P_{0}=\sum_{i=1}^{N} p_{i, 0} q_{i, 0}
$$

where $p_{i, 0}$ is the premium for a policy in the $i$ th line and $q_{i, 0}$ is the quantity sold in the $i$ th line. We assume policies in each line of business are homogeneous with respect to the loss distribution. The production cost for policies sold is assumed to be a function of quantities sold across all lines

$$
c_{0}=c\left(q_{1,0}, \ldots, q_{N, 0}\right) .
$$

These include expenses for underwriting, administration, marketing, and broker commissions. The cash value of the assets at time 0 is then given by

$$
V_{0}=R_{0}+P_{0}-c_{0}
$$

In order to determine the actuarial value of the liabilities it is necessary to value the time 1 payoffs. The time 1 random loss payoff for a policy in the $i$ th line is denoted by $L_{i, 1}$ and the total random losses at time 1 is denoted by $L_{1}$ with

$$
L_{1}=\sum_{i=1}^{N} L_{i, 1} q_{i, 0}
$$

The value of total liabilities at time 0 are valued using a market based risk neutral valuation assumption. We assume that there exists a risk-neutral $Q$ probability measure that values all cash flows in the model. This is consistent with financial pricing theory under the assumption of arbitrage free markets (Cochrane [2]). Our model is incomplete because of frictional costs. Because we require the valuation model to be arbitrage free, a risk-neutral $Q$ probability measure exists, but this measure may not be unique. We have

$$
L_{0}=e^{-r} \sum_{i=1}^{N} \mu_{i, 1} q_{i, 0},
$$

where

$$
\mu_{i, 1}=E^{Q}\left[L_{i, 1}\right]
$$

is the (risk-adjusted or market consistent) expected value of the insurance loss per policy for the $i$ th line of business and $r$ is the continuous compounding risk free rate of interest. 
Assets accumulate according to a random return of $r_{V}$ so that the asset payoffs at time 1 are determined by the random return on the asset portfolio. We have

$$
V_{1}=V_{0} e^{r_{V}}
$$

Given the cash initially invested from capital and premiums the initial value is related to the time 1 payoff under fair pricing in asset markets by,

$$
V_{0}=e^{-r} E^{Q}\left[V_{1}\right] .
$$

Although all the values are based on market values and are consistently valued using risk neutral valuation, there is an important balance sheet component still to be included. The model must allow for limited liability since if there are insufficient assets to meet liabilities then the policyholders will have their claims reduced by the shortfall. This is the risk of insolvency and importantly reflects the financial quality of the insurer.

To allow for the risk of insolvency, at time 1 policyholders with claims payable are assumed to receive claim amounts contingent on the value of the assets of the insurer's balance sheet. Each line has full payment on all its policies in the event that asset exceed liabilities so that

$$
L_{1}=\sum_{i=1}^{N} L_{i, 1} q_{i, 0} \text { if } A_{1} \geq L_{1}
$$

otherwise they are entitled to the assets

$$
V_{1} \text { if } V_{1}<L_{1} .
$$

Payoffs to shareholders will also depend on the balance sheet at time 1 reflecting their limited liability. If assets are insufficient to meet liabilities then shareholders do not have to subscribe more capital at time 1 to meet the shortfall. Shareholder payoffs are then

$$
V_{1}-L_{1} \text { if } V_{1} \geq L_{1}
$$

and

$$
0 \text { if } V_{1}<L_{1} \text {. }
$$

In the event of insolvency, the shortfall of assets over liabilities that the policyholders have to bear in reduced claim payments is

$$
D_{1}=\max \left[L_{1}-V_{1}, 0\right]
$$


and we define

$$
D_{0}=e^{-r} E^{Q}\left[D_{1}\right]
$$

where $D_{0}$ is the insolvency or default put option value. The default ratio, $d_{0}$, is defined as the default risk per dollar of liabilities where $D_{0}=L_{0} d_{0}$. The default ratio can be valued as a put option on the asset-liability ratio

$$
d_{0}=e^{-r} E^{Q}\left[d_{1}\right]
$$

where

$$
d_{1}=\max \left[1-\Lambda_{1}, 0\right]
$$

and the asset-liability ratio is

$$
\Lambda_{1}=\frac{V_{1}}{L_{1}} .
$$

If we denote the policyholder claims payoff allowing for insolvency at time 1 by

$$
\begin{aligned}
H_{1} & =\min \left[L_{1}, V_{1}\right] \\
& =L_{1}-D_{1}
\end{aligned}
$$

then at time 0 this insolvency adjusted value is given by

$$
\begin{aligned}
H_{0} & =e^{-r} E^{Q}\left[L_{1}-D_{1}\right] \\
& =L_{0}-D_{0} \\
& =L_{0}\left(1-d_{0}\right) .
\end{aligned}
$$

For shareholders, if we denote the payoff to the equity at time 1 by $E_{1}$ then

$$
\begin{aligned}
E_{1} & =\max \left[V_{1}-L_{1}, 0\right] \\
& =V_{1}-L_{1}+D_{1} .
\end{aligned}
$$

and at time 0 equity value, denoted by $E_{0}$, is

$$
\begin{aligned}
E_{0} & =e^{-r} E^{Q}\left[V_{1}-L_{1}+D_{1}\right] \\
& =V_{0}-L_{0}+D_{0} .
\end{aligned}
$$

The effect of explicitly taking limited liability into account, as shown in Equation (1), is that the market value of policyholder claims is reduced by the value of the default put option. The economic value of liabilities is given by $H_{0}$. For shareholders, the default put results in an increase in the value of payoffs, as shown by Equation (2). 
TABLE 1

THE ECONOMIC INSOLVENCY ADJUSTED BALANCE SHEET.

\begin{tabular}{l|l}
\hline \hline Assets & Economic Liabilities \\
\hline$V_{0}$ & $L_{0}-D_{0}$ \\
& Equity \\
& $V_{0}-L_{0}+D_{0}$ \\
\hline \hline
\end{tabular}

Allowing for the effect of limited liability on payoffs results in the economic insolvency adjusted balance sheet shown in Table 1. Surplus is defined as the difference between the value of assets and the value of liabilities ignoring the default put option value. Equity is the difference between the assets and the liabilities allowing for the value of the default put option. This balance sheet is similar to Sherris [26] and Sherris and van der Hoek [27] except that the model formally includes production costs and assumes premium income is determined by price and quantity sold by line.

\subsection{Allowing for Market Frictions}

We now extend the model analyzed in Sherris [26] and Sherris and van der Hoek [27] by explicitly including frictional costs. Capital is assumed to be costly to hold and at time 1 frictional costs are incurred in the form of deadweight losses from taxes, agency costs of capital, and costs of financial distress.

Taxes are assumed to be paid on the profit of the insurer. The profit of the insurer at time 1 consists of investment income and underwriting profit if the insurer is solvent. In the event of insolvency there is assumed to be a tax benefit from any losses of the initial investment of the shareholders. Shareholder profit at time 1 is the equity value $E_{1}$ less the initial capital invested in the firm,

$$
E_{1}-R_{0}=V_{1}-L_{1}+D_{1}-R_{0} .
$$

Corporate taxes, including tax benefit from losses, are assumed to be

$$
\tau_{1}\left(E_{1}-R_{0}\right)=\tau_{1}\left(V_{1}-L_{1}+D_{1}-R_{0}\right) .
$$

Shareholder agency costs of capital arising from management are assumed to be proportional to the amount of capital initially subscribed and equal to

$$
\tau_{2} R_{0} .
$$

Bankruptcy costs are assumed to be zero if the insurer is solvent at time 1 and can pay all liabilities, otherwise they are assumed to be a percentage of the 
shortfall of assets over liabilities reflecting the size of the insolvency. Thus assumed bankruptcy costs are

$$
0 \text { if } V_{1} \geq L_{1}
$$

or

$$
f\left(L_{1}-V_{1}\right) \text { if } V_{1}<L_{1} .
$$

Altman [1] and Warner [34] report bankruptcy costs as percentages of firm value and shareholder value respectively. We assume bankruptcy costs will be higher the larger the shortfall of assets to liabilities. The time 1 payoffs to policyholders allowing for bankruptcy costs is then

$$
H_{1} \text { if } V_{1} \geq L_{1}
$$

and

$$
H_{1}-f\left(L_{1}-V_{1}\right) \text { if } V_{1}<L_{1} \text {. }
$$

By setting Equation (3) to zero we obtain

$$
\frac{V_{1}}{L_{1}}=\frac{f}{1+f} .
$$

which determines the bankruptcy cost percentage that would eliminate any excess of assets over liabilities. Equation (4) defines a critical shortfall ratio, measured by the asset-liability ratio, at which assets available to policyholders in the event of bankruptcy will be fully consumed by bankruptcy costs and policyholders will receive no payment. Table 2 demonstrates that a bankruptcy cost assumption of $10 \%$ implies that if liabilities were to exceed assets by a ratio of 11:1, then policyholders would not receive any payoff after meeting bankruptcy costs. Alternatively, bankruptcy costs of $50 \%$ imply that reaching the

TABLE 2

CRITICAL BANKRUPTCY RATIOS FOR DIFFERENT VALUES OF $f$.

\begin{tabular}{cc}
\hline \hline$f$ & Critical Shortfall Ratio \\
\hline 0.0 & - \\
0.1 & $11: 1$ \\
0.2 & $6: 1$ \\
0.3 & $13: 3$ \\
0.4 & $7: 2$ \\
0.5 & $3: 1$ \\
\hline \hline
\end{tabular}


TABLE 3

THE ECONOMIC BALANCE SHEET ALLOWING FOR INSOLVENCY AND FRICTIONAL COSTS.

\begin{tabular}{ll}
\hline \hline Assets & Economic Liabilities \\
\hline$V_{0}$ & $L_{0}-(1+f) D_{0}$ \\
& $+e^{-r} \tau_{1}\left(E_{1}-R_{0}\right)$ \\
& $+e^{-r} \tau_{2} R_{0}$ \\
& Equity \\
& $V_{0}-L_{0}+(1+f) D_{0}$ \\
& $-e^{-r} \tau_{1}\left(E_{1}-R_{0}\right)$ \\
& $-e^{-r} \tau_{2} R_{0}$ \\
\hline \hline
\end{tabular}

critical ratio is much more likely as liabilities only have to exceed assets by a ratio of 3:1 before firm assets are fully consumed by bankruptcy costs.

By the definition of bankruptcy costs their value at time 0 is determined by the default put option value and equal to

$$
f D_{0} .
$$

The value of policyholder claims at time 0 allowing for bankruptcy costs becomes

$$
H_{0}=L_{0}-(1+f) D_{0}
$$

Bankruptcy costs reduce the value of policyholder claims but do not explicitly affect shareholder payoffs.

For shareholders, allowing for corporate tax and agency costs, the time 1 payoff is

$$
E_{1}=\left(V_{1}-L_{1}+D_{1}\right)\left(1-\tau_{1}\right)+\left(\tau_{1}-\tau_{2}\right) R_{0}
$$

and at time 0 the shareholder equity value is

$$
E_{0}=\left(V_{0}-L_{0}+D_{0}\right)\left(1-\tau_{1}\right)+e^{-r}\left(\tau_{1}-\tau_{2}\right) R_{0} .
$$

Taxes and agency costs reduce the value of shareholder claims. The market value balance sheet allowing for insolvency and frictional costs is given in Table 3.

\subsection{Maximizing Insurer Value}

The optimal balance sheet is determined by selecting the insurer capital subscribed and the by-line prices that maximize EVA. We use the terminology EVA 
to differentiate the model used here from many other value maximization approaches. The objective is not to maximize insurer shareholder value but to maximize the firm value added from writing insurance business over and above the value of the equity subscribed. Value is added by writing insurance business at profit loads above the risk adjusted expected value of claims and costs, allowing for insolvency, reflecting policyholder demand elasticities and preferences for financial quality. Frictional costs of capital reduce value and holding too much capital increases these costs. However, holding too low a level of capital impacts market demand and there is a trade-off because of frictional costs. This trade-off produces an optimal level of capitalization and an optimal pricing strategy.

\subsubsection{Enterprise Value Added}

EVA is formally defined as the difference between the value of equity at time 0 , given by Equation (6), and the amount of initial capital subscribed allowing for frictional costs and insolvency or,

$$
E V A_{0}=E_{0}-R_{0} .
$$

The insurer's objective is to maximize EVA by selecting the by-line prices and capital subscribed

$$
\begin{aligned}
\max _{R_{0}, p_{i, 0}}\left\{E V A_{0}\right\} & =\max _{R_{0}, p_{i, 0}}\left\{E_{0}-R_{0}\right\} \\
& =\max _{R_{0}, p_{i, 0}}\left\{\begin{array}{c}
\left(P_{0}-c_{0}-L_{0}\left(1-d_{0}\right)\right)\left(1-\tau_{1}\right) \\
-\left(\left(1-e^{-r}\right) \tau_{1}+e^{-r} \tau_{2}\right) R_{0}
\end{array}\right\} .
\end{aligned}
$$

Equation (7), consists of two components. The first is the profits from insurance underwriting net of corporate taxes, while the second is the frictional costs of capital.

Following Zanjani [36], the first order conditions for optimal capital and prices in our model are as follows. An equation from differentiating with respect to capital

$$
0=\sum_{i=1}^{N}\left(p_{i, 0}-c_{i, 0}^{\prime}-e^{-r} \mu_{i, 1}\left(1-d_{0}\right)\right) \frac{\partial q_{i, 0}}{\partial d_{0}} \frac{\partial d_{0}}{\partial R_{0}}+L_{0} \frac{\partial d_{0}}{\partial R_{0}}-\delta
$$

and $N$ equations from differentiating with respect to prices for each line

$$
\begin{aligned}
0= & q_{i, 0}+\frac{\partial q_{i, 0}}{\partial p_{i, 0}}\left(p_{i, 0}-\frac{\partial c_{0}}{\partial q_{i, 0}}-e^{-r} \mu_{i, 1}\left(1-d_{0}\right)\right) \\
& +\sum_{j=1}^{N}\left(p_{j, 0}-\frac{\partial c_{0}}{\partial q_{j, 0}}-e^{-r} \mu_{j, 1}\left(1-d_{0}\right)\right) \frac{\partial q_{j, 0}}{\partial d_{0}} \frac{\partial d_{0}}{\partial p_{i, 0}}+L_{0} \frac{\partial d_{0}}{\partial p_{i, 0}}
\end{aligned}
$$


where

$$
\delta=\frac{\left(1-e^{-r}\right) \tau_{1}+e^{-r} \tau_{2}}{1-\tau_{1}} .
$$

These equations must be solved simultaneously and cannot be solved analytically. It is also necessary to include in the optimization constraints to ensure that the balance sheet values for the put option and the value of the liabilities are equal to the risk adjusted value of the time 1 payoffs. These constraints make the first order conditions more complex and the optimization must be solved numerically.

\section{DAta And Model Insurer}

We construct a model insurer representative of a diversified multi-line insurer writing business in the Australian general insurance industry. Although the data is representative of an Australian insurer, the general model is representative of insurers in many countries. The implications for risk based capital and pricing apply to property-casualty or general insurance companies more broadly. Since we allow for a range of frictional costs, the study provides a broad understanding of the impact of these costs on optimal strategies. The model is similar to previous studies of the industry, for example SutherlandWong and Sherris [30] and Tang and Valdez [32] in Australia and also D'Arcy and Gorvett [8]. Although the aim has been to construct a realistic model insurer, many simplifying assumptions are made. The model has been calibrated to industry data and published studies. This is the first public study that we are aware of that assesses the relative impact of different types of frictional costs on enterprise value, pricing strategies, and the importance of each for risk based capital and risk management. We also formally incorporate and quantify price elasticities in insurer decision making and the impact on profit margins and capitalization.

\subsection{Data}

The data used to calibrate the model insurer were derived from the following sources.

- Australian Prudential Regulation Authority (APRA), Half Yearly General Insurance Bulletin, December 1998 to December 2001.

- Tillinghast-Towers Perrin, Research and Data Analysis Relevant to the Development of Standards and Guidelines on Liability Valuation for General Insurance, November 2001.

- Reserve Bank of Australia (RBA), S\&P/ASX 200 Accumulation Index, January 1979 to September 2006. 
- ABN AMRO, Government and Semi-Government Bonds Total Return Index, January 1990 to September 2006.

\subsubsection{The Model Insurer}

The Business Mix. In order to construct a well diversified portfolio of a typical insurer, the five largest individual lines by net premium revenue were included in the insurer portfolio. The lines included in the business mix are as follows.

- Domestic motor

- Household

- Fire \& ISR

- Public and product liability

- CTP

The December 2005 issue of the APRA Half Yearly Bulletin indicate these lines alone represent $68 \%$ of industry gross premium revenue. Five lines of business represent a diversified multi-line insurer. The portfolio includes business lines with claims of a variety of different tail lengths, and include classes of business that are personal, commercial, and compulsory. The characteristics of each line of business is summarized in Table 4.

TABLE 4

THE BUSINESS LINES OF THE MODEL INSURER AND INDUSTRY WEIGHTINGS.

\begin{tabular}{lllc}
\hline \hline \multicolumn{1}{c}{ Lines } & Category & \multicolumn{1}{c}{ Type } & Gross Premium Revenue \\
\hline Motor & Short tail & Personal & $21.7 \%$ \\
Household & Short tail & Personal & $14.5 \%$ \\
Fire \& ISR & Intermediate & Commercial & $12.2 \%$ \\
Liability & Long tail & Commercial & $8.6 \%$ \\
CTP & Long tail & Compulsory & $10.6 \%$ \\
\hline \hline
\end{tabular}

Assets. The insurer is assumed to hold a diversified portfolio invested in cash, bonds, and stocks similar to that of a typical insurer. The distributional assumptions used for the asset and liabilities of the model insurer are similar to those in Sherris and van der Hoek [27]. Asset and liability values are assumed to be log-normally distributed. Table 5 summarizes the parameter assumptions for the distribution of returns for each asset class. We focus on determining the optimal capital structure and pricing strategy for a typical asset portfolio. We do not optimize over the asset portfolio. However, we do consider the impact of asset-liability matching through the correlation between asset and liability payoffs but do not explicitly determine the optimal asset portfolio. 
TABLE 5

Distribution ASSUMPTION OF ANNUAL LOG-RETURNS BY ASSET CLASS.

\begin{tabular}{lccc}
\hline \hline Assets & Distribution of Annual Log-Returns & $\mu$ & $\sigma$ \\
\hline Cash & Deterministic & 0.05 & - \\
Bonds & Lognormal & 0.09336 & 0.04927 \\
Stocks & Lognormal & 0.16263 & 0.15652 \\
\hline \hline
\end{tabular}

Cash is assumed to be risk-free, uncorrelated with risky assets, and accumulates at the continuously compounding rate of $5 \%$ p.a. This assumption is consistent with 30-day bank accepted bills over the sample period. Bond logreturns are assumed to be normally distributed and are estimated using the ABN AMRO Total Return Index, which tracks a diversified portfolio of government and semi-government bonds. This index is used as a proxy for the fixed interest investments typically held by general insurers. This index does not include corporate bonds and can be viewed as a conservative fixed interest investment. Maximum likelihood parameter estimates for monthly bond logreturns from 1990 to 2006 are shown in Table 6.

TABLE 6

PARAMETER ESTIMATES FOR DISTRIBUTION OF MONTHLY BOND LOG-RETURNS.

\begin{tabular}{cccc}
\hline \hline$\mu_{B}^{12}$ & Standard Error & $\sigma_{B}^{12}$ & Standard Error \\
\hline 0.00778 & 0.00101 & 0.01422 & 0.00071 \\
\hline \hline
\end{tabular}

To annualize these estimates, monthly returns are assumed to be independent and identically distributed. This approach ignores volatility clustering and the correlation of returns over time so the parameter estimates may understate the volatility of returns. However, for this single-period model the effect of dependent asset returns is not an issue. This would have to be carefully considered for a multi-period model.

To estimate returns on stocks, monthly data on the S\&P/ASX 200 from December 1979 to August 2006 is used to fit a normal distribution to historical log-returns. Table 7 displays results for maximum likelihood parameter estimates.

TABLE 7

PARAMETER ESTIMATES FOR DISTRIBUTION OF MONTHLY EQUITY LOG-RETURNS.

\begin{tabular}{cccc}
\hline \hline$\mu_{E}^{12}$ & Standard Error & $\sigma_{E}^{12}$ & Standard Error \\
\hline 0.01355 & 0.00253 & 0.04518 & 0.00179 \\
\hline \hline
\end{tabular}


Again to obtain annual estimates, we assume monthly returns are independent and identically distributed.

Data between 1990 and 2006 on the ABN AMRO Total Return Index and the S\&P/ASX 200 was used to estimate the correlation between bonds and equity. These estimates are comparable to studies of correlations between stocks and bonds, for example, see Li [17]. The assumed annualized asset correlation matrix is shown in Table 8 .

TABLE 8

ASSET CORRELATION MATRIX.

\begin{tabular}{l|ccc}
\hline \hline Assets & Cash & Bonds & Equity \\
\hline Cash & 1.00 & 0.00 & 0.00 \\
Bonds & 0.00 & 1.00 & 0.27 \\
Equity & 0.00 & 0.27 & 1.00 \\
\hline \hline
\end{tabular}

The asset mix assumed for the model insurer is shown in Table 9. This is based on APRA industry data.

TABLE 9

THE ASSET MIX OF THE MODEL INSURER.

\begin{tabular}{lc}
\hline \hline Assets & Portfolio Weight \\
\hline Cash & $15 \%$ \\
Bonds & $65 \%$ \\
Stocks & $20 \%$ \\
\hline \hline
\end{tabular}

Log-returns on the overall asset portfolio based on the estimated return distributions have an expected value of $\mu_{V}=10.09 \%$ and a standard deviation of $\sigma_{V}=5.04 \%$. The total level of return and volatility are representative of historical data and ensure the numerical results are realistic.

Liabilities. Consistent with empirical evidence, for example Cummins and Phillips [5], underwriting risks are assumed to have low systematic risk and all expectations are discounted at the risk-free rate. A simple modification would be required to include risk premiums for liability valuation that differ by line in order to include a systematic component.

The expected outstanding claims liability on a per policy basis is estimated from APRA data. To estimate the expected claim per policy for each line of business, the outstanding claims liability was averaged across the number of policies in-force. The mean of these estimates over the sample period is used to calibrate the model insurer. Parameter assumptions are given in Table 10. 
The outstanding claims liability is determined assuming claims are lognormally distributed. The log-normal distribution is commonly used by practitioners to model general insurance liability distributions and is also used in Hitchcox et al. [15]. In order to estimate the parameters of the log-normal distribution for each line of business we use the Tillinghast estimate of the coefficient of variation (CV) for outstanding claims liability by line of business from industry data between 1997 and 2001 and the mean outstanding claim liability for each line reported by APRA over this sample period. The average outstanding claims liability for each line of business which are estimated from APRA's Half Yearly Bulletin for the period December 1997 to December 2001 are shown in Table 10. The CV by line of business from the Tillinghast report are also given in Table 10. The properties of the log-normal distribution allow the variance for each line of business to be determined directly from the $\mathrm{CV}$ using the result

$$
C V_{i}=\left(e^{\sigma_{1}^{2}}-1\right)^{\frac{1}{2}}
$$

and values for $\sigma_{i}$ are given in Table 10. The model assumptions only require the standard deviation of the log of outstanding claims liability to be specified on a per policy basis. The mean and variance for the log of outstanding claims liability by line is determined by the quantities of business written. The assumption of log-normal losses allows a determination of the volatility of by line losses based only on the coefficient of variation.

TABLE 10

EXPECTED OUtSTANDING Claims AND TILLINGHAST CVS By LINE OF BUSINESS.

\begin{tabular}{lccc}
\hline \hline Line & $\begin{array}{c}\text { Expected Outstanding Claims } \\
\text { Liability per Policy }\end{array}$ & $\begin{array}{c}\text { Tillinghast } \\
\text { CVs }\end{array}$ & $\begin{array}{c}\text { Lognormal } \\
\sigma_{i}\end{array}$ \\
\hline Motor & 203 & $11.1 \%$ & 0.1107 \\
Household & 105 & $13.2 \%$ & 0.1314 \\
Fire \& ISR & 201 & $14.1 \%$ & 0.1403 \\
Liability & 256 & $19.0 \%$ & 0.1883 \\
CTP & 249 & $23.5 \%$ & 0.2318 \\
\hline \hline
\end{tabular}

The Tillinghast correlation matrix is used for the dependence assumed between liabilities by line of business and is given in Table 11 .

Asset Liability Dependence. We are not aware of any published studies of correlations between the asset portfolio and the outstanding claims liability by line of business for general insurers in Australia. Estimating these correlations requires large amounts of reliable data. For an empirical study based on U.S. 
TABLE 11

TILLINGHAST CORRELATION MATRIX.

\begin{tabular}{l|ccccc}
\hline \hline Lines & Motor & Household & Fire \& ISR & Liability & CTP \\
\hline Motor & 1.00 & 0.75 & 0.40 & 0.00 & 0.55 \\
Household & 0.75 & 1.00 & 0.35 & 0.00 & 0.00 \\
Fire \& ISR & 0.40 & 0.35 & 1.00 & 0.00 & 0.00 \\
Liability & 0.00 & 0.00 & 0.00 & 1.00 & 0.35 \\
CTP & 0.55 & 0.00 & 0.00 & 0.35 & 1.00 \\
\hline \hline
\end{tabular}

data, see Cummins, Lin, and Phillips [4]. Our initial analysis assumes the correlations between assets and liabilities are zero, however, we examine how this dependence affects the results through a sensitivity analysis.

Underwriting Expenses. We assume constant per policy underwriting expenses typical of a large general insurer and make no allowance for any potential benefits of economies of scale. Data on underwriting expenses was sourced from APRA's Half Yearly Bulletin. For each line we assume expenses are fixed per policy and we estimate this by the sample mean of the average expense per policy for the general insurance industry between December 1997 and December 2001. Table 12 displays the by-line per policy underwriting expenses assumed for the model insurer.

TABLE 12

UNDERWRITING EXPENSES PER POLICY.

\begin{tabular}{lc}
\hline \hline Lines & Underwriting Expense \\
\hline Motor & 66.6 \\
Household & 65.6 \\
Fire \& ISR & 152.4 \\
Liability & 125.2 \\
CTP & 44.7 \\
\hline \hline
\end{tabular}

\subsubsection{The Demand for Insurance}

Allowing for Inelastic Demand. The model formally includes policyholder price elasticity to reflect market imperfections in the insurance market. The demand for different lines of business is also assumed to be sensitive to firm-wide default risk so that policyholders care about financial quality. Phillips, Cummins, and Allen [25] find empirically that premiums are lower for insurers with higher 
insolvency option values based on U.S. data between 1988-1992 and the amount varied by long and short tail lines of business. In a more recent study based on U.S. data between 1997-2004, Cummins, Lin, and Phillips [4] also find strong evidence that insurance prices are inversely related to insolvency risk as measured by A.M. Best's financial ratings.

The demand function for the $i$ th line of business determines the quantity of insurance sold for each of the $N$ lines of business. For a price of $p_{i, 0}$ per unit of insurance the demand, $q_{i, 0}$, is assumed to be a function of price, default risk, and bankruptcy costs

$$
q_{i, 0}=q\left(p_{i, 0}, d_{0}, f\right)
$$

where $\frac{\partial q_{i, 0}}{\partial p_{i, 0}}<0, \frac{\partial q_{i, 0}}{\partial d_{0}}<0$, and $\frac{\partial q_{i, 0}}{\partial f}<0$. Higher prices are assumed to result in reduced sales, as do higher levels of default risk and bankruptcy costs. The capitalization of the insurer determines the financial quality of the insurer. We use the value of the insolvency put option for the financial quality of the insurer. Policyholder losses in the event of insolvency also include bankruptcy costs and it is assumed that the size of these frictional costs also influence the demand for insurance.

In a market where the demand for insurance is imperfectly elastic and policyholders care about financial quality, the demand function faced by the insurer will be downward sloping with respect to both price and default risk. We assume a linear demand function for the $i$ th line of business,

$$
q_{i, t}=q\left(p_{i, t}, d_{t}, f\right)=\alpha_{i} \max \left[1+\beta_{i} p_{i, t}+\gamma_{i}(1+f) d_{t}, 0\right] .
$$

The demand function $\max \left[1+\beta_{i} p_{i, t}+\gamma_{i}(1+f) d_{t}, 0\right]$ ranges in value from zero to one. It can be interpreted as a measure of policyholder preference for purchasing an insurance policy in the $i$ th line from the model insurer given its price and financial quality. The total demand is the product of a scale parameter $\alpha_{i}$ that determines the maximum volume of business demanded for the $i$ th line for the model insurer and the policyholder preference for the insurer given its characteristics. As prices rise, the demand for insurance will fall and $\beta_{i}<0$. Similarly, as default risk increases policyholders will demand less insurance and $\gamma_{i}<0$. The sensitivity to default risk is also assumed to reflect the bankruptcy costs that policyholders bear in the event of insolvency on a proportionate basis.

The $\alpha_{i}$ is calibrated to reflect the differences in the number of policies sold in the different lines of business and to ensure the model is representative of a large and diversified insurer. APRA data indicates that CTP insurance typically has a higher number of policies on issue than liability insurance. This partly reflects the fact that the former is compulsory. The relative volume of business underwritten by lines is based on the average number of policies for the industry over the period December 1997 to December 2001 from APRA 
TABLE 13

ASSUMED SCALE PARAMETERS BY LINE OF BUSINESS.

\begin{tabular}{lcc}
\hline \hline Lines & $\begin{array}{c}\text { Average No. of } \\
\text { Policies }\end{array}$ & $\begin{array}{c}\alpha_{i} \\
\text { (thousands) }\end{array}$ \\
\hline Motor & 9,962 & 19,923 \\
Household & 10,384 & 20,768 \\
Fire \& ISR & 2,441 & 4,883 \\
Liability & 3,083 & 6,165 \\
CTP & 5,972 & 11,944 \\
\hline \hline
\end{tabular}

data. The average number of policies was multiplied by a factor of 20 in order to produce the level of demand typical of a large insurer. This results in the model insurer underwriting approximately $10 \%$ of total industry liabilities. The values for $\alpha_{i}$ are shown in Table 13.

Price. There are no published studies that we are aware of that provide estimates of general insurer price elasticities of demand for the lines of business in our model insurer. The demand for insurance falls as prices rise and the gradient with respect to price depends on many factors including policyholder preferences, line of business, competitiveness of the market, available information, and search costs. In order to capture market imperfections and reflect reasonable price elasticities for each line we calibrate the policyholder demand function by determining a margin above per policy expected claims and costs at which policyholder demand is assumed to be zero. This is the point at which the insurer is assumed to be priced out of the market.

For personal lines we assume policyholders have high search costs and the margin above expected cost at which demand will go to zero will be higher than for commercial lines. The demand for insurance in compulsory lines is assumed to be the least elastic since policyholders must purchase this insurance by law. The values assigned to $m_{i}$ are shown in Table 14 .

TABLE 14

MAXIMUM PROFIT MARGINS ALLOWED OVER PER POLICY EXPECTED COST.

\begin{tabular}{lrc}
\hline \hline Lines & $m_{i}$ & Max Price \\
\hline Motor & $14 \%$ & 296.56 \\
Household & $14 \%$ & 187.66 \\
Fire \& ISR & $8 \%$ & 371.07 \\
Liability & $8 \%$ & 400.26 \\
CTP & $20 \%$ & 337.76 \\
\hline \hline
\end{tabular}


Note that these assumptions are representative of a reasonably price competitive insurance market. It does not take very large margins to drive assumed demand to zero. In a perfect and fully competitive market any increase in price over and above expected cost would be assumed to drive demand to zero. Under these assumptions, $\beta_{i}$ is given by

$$
\beta_{i}=-\frac{1}{\left(1+m_{i}\right)\left(e^{-r} \mu_{i, 1}+c_{i, 0}^{\prime}\right)}
$$

and the values for $\beta_{i}$ are shown in Table 15 .

TABLE 15

ASSUMED PRICE SENSITIVITY COEFFICIENTS BY LINE OF BUSINESS.

\begin{tabular}{lc}
\hline \hline Lines & $\beta_{i}$ \\
\hline Motor & -0.00337 \\
Household & -0.00532 \\
Fire \& ISR & -0.00270 \\
Liability & -0.00250 \\
CTP & -0.00296 \\
\hline \hline
\end{tabular}

Default Risk. Phillips, Cummins, and Allen [25] use U.S. data between 19881992 and estimate that a 1\% increase in the insolvency put ratio will lower the premiums $2.0 \%$ for long tail lines of business and $11.5 \%$ for short tail lines of business. Policyholder demand for insurance will fall to zero when, $d_{t}=1$. This means that the insurance policy is worthless as the probability of default is almost certain and demand will be zero. We assume that the coefficient for $\gamma_{i}=-1$. Under this assumption the percentage change in quantity will be proportional to the by-line default option value as a per cent of the fair value of liabilities. Other values of $\gamma_{i}$ may be plausible since, due to information asymmetries, policyholders may not be able to correctly evaluate the insolvency risk of an insurance company. We will examine the sensitivity of the results to this assumption.

\subsubsection{Pricing the Option to Default}

The value of the default put option is given by

$$
D_{0}=L_{0} d_{0} \text {. }
$$

Since we assume that assets and liabilities have dependent log-normal distributions, the default put option is equivalent to an exchange option or a put 
option on the asset liability ratio of the insurer (Myers and Read [23], Cummins and Danzon [6]). Using the Margrabe [19] exchange option pricing formula, the value of the default option ratio is given by

$$
d_{0}=\Phi(z)-\Lambda_{0} \Phi(z-\sigma)
$$

with

$$
\begin{gathered}
\Lambda_{0}=\frac{V_{0}}{L_{0}}, \\
z=\frac{-\ln \left(\Lambda_{0}\right)}{\sigma}+\frac{1}{2} \sigma .
\end{gathered}
$$

The volatility is given by

$$
\sigma=\sqrt{\sigma_{L}^{2}+\sigma_{V}^{2}-2 \sigma_{L V}}
$$

where

$$
\begin{gathered}
\sigma_{L}^{2}=\sum_{i=1}^{N} \sum_{j=1}^{N} x_{i} x_{j} \sigma_{i} \sigma_{j} \rho_{i j}, \\
\sigma_{L V}=\sum_{i=1}^{N} x_{i} \sigma_{i} \sigma_{V} \rho_{i V},
\end{gathered}
$$

$\rho_{i j}$ is the loss correlation between the log growth rate of the lines of business, $\rho_{i V}$ is the correlation between the log asset return and the log growth rate of each line of business, and $x_{i}$ is the proportion of value of liabilities in the $i$ th line

$$
x_{i}=\frac{e^{-r} \mu_{i, 1} q_{i, 0}}{\sum_{j=1}^{N} e^{-r} \mu_{j, 1} q_{j, 0}} .
$$

\subsubsection{Default Values by Line of Business}

In order to determine pricing by line, the default value of each line of business is determined. The by-line default ratios are determined using

$$
d_{i, 0}=\Phi\left(z_{i}\right)-\Lambda_{0} \Phi\left(z_{i}-\sigma_{\Lambda_{0}}\right)
$$

where

$$
z_{i}=\frac{-\left(\ln \Lambda_{0}+\mu_{i \Lambda_{0}}\right)}{\sigma}+\frac{1}{2} \sigma
$$


and

$$
\mu_{i \Lambda_{0}}=\sigma_{L}^{2}-\sigma_{L} \sigma_{V} \rho_{L V}+\sigma_{i} \sigma_{V} \rho_{i V}-\sigma_{i} \sigma_{L} \rho_{i L}
$$

These results are derived in Sherris and van der Hoek [27]. Note that $\sigma$ and $\sigma_{L}$ are defined by Equations (9) and (10) respectively. This approach ensures that the allocation of the firm-wide default put option to line of business reflects the payoffs to policyholders and is used to determine the fair value of liabilities by line for the model insurer.

\subsubsection{Numerical Methods and the Optimization Procedure}

Solving the Optimal Balance Sheet for Value Maximization. The model requires numerical techniques in order to determine the optimal capitalization and prices because of the non-linear relationships and the interdependencies in the model. For a given set of values for capital structure and prices it is possible to determine the balance sheet structure. The financial quality of the insurer, measured by the default put option, will influence the premium income through the demand for insurance. The value of the default put option is also a function of balance sheet items. Because of this, an iterative approach is required to construct a balance sheet so that values are both internally consistent and consistent with time 1 payoffs. Since the objective is to determine the capitalization and prices by line that produce the maximum EVA, it is necessary to use a numerical procedure to search for the optimal values for capital subscribed and prices by line.

The following approach is used to construct the balance sheet for a given set of values for capital and prices by line to ensure the value constraints are met.

1. Starting values for prices $p_{i, 0}$ for $i=1, \ldots, N$ and initial capital $R_{0}$ are determined.

2. The liabilities and assets for the balance sheet are valued based on the equations in Section 2.

3. The liabilities and assets values for the balance sheet are used to determine the default put option value using the Margrabe [19] exchange option pricing formula, as described in Section 3.

4. The value of the default put option is solved for numerically in order to satisfy value constraints and produce a consistent balance sheet.

5. EVA is evaluated based on balance sheet items and default put option.

EVA is maximized using a direct search method. Prices $p_{i, 0}$ for $i=1, \ldots, N$ and initial capital $R_{0}$ are varied and the balance sheet is constructed to ensure value constraints are met as above. This process is iterated until EVA converges to a maximum. 
Optimizing Insurer Value Using a Direct Search Method. To maximize EVA a direct search method was used. Direct search is a non-derivative based method that searches for a maximum around a set of starting coordinates. In particular, a pattern search algorithm with non-linear constraints was used for the optimization. For an initial point, the algorithm creates a set of points to search, called a mesh, by adding a scalar multiple of a pattern of vectors. In order to ensure the algorithm produced an optimal value, we repeated each optimization with a number of different starting values to ensure the objective function converged to a global maximum. For further detailed information on the method used see Torczon [33] and Lewis and Torczon [16].

\section{Results And Discussion}

\subsection{Frictionless Markets and No Preferences for Financial Quality}

We begin by considering an EVA maximizing insurer in a market with imperfectly elastic demand but without frictional costs. Policyholders are assumed to have no preference for financial quality and do not discriminate between insurers with high or low risk of default, so that for $i=1, \ldots, N$

$$
\gamma_{i}=\frac{\partial q_{i, t}}{\partial d_{0}}=0 .
$$

The optimal balance sheet is given in Table 16 where items are expressed in both dollars and as a percentage of total assets. Assets consist of subscribed capital and premiums net of underwriting expenses and frictional costs. Loss reserves are the fair or economic value of liabilities adjusted for the default value by line of business. The item NPV of Profits is the excess value of premiums charged over the expected claims and underwriting costs and reflects the elasticity of demand for the insurer. It is interesting to note that for this hypothetical case, because demand for insurance is not influenced by the capital structure of the firm, total capital is $9.1 \%$ of total assets and the insurer does not subscribe risk capital initially. Capital is fully generated from the profit margins in premiums and the default put option value. Since policyholders are assumed to have no preference for financial quality, the insurer's optimal strategy is not to subscribe capital. The default option value is large at $2.6 \%$ of total assets.

When policyholders consider the financial quality of the insurer, the appropriate measure of default risk is the firm-wide default ratio. The default ratio is the value of the default put option as a proportion of total liabilities. This is because if the company defaults on one policy, it will default on all policies. Policyholders bear the default risk of the entire company and not the marginal default risk of any single line of business. For the purposes of by-line pricing, the individual default payoff of each line is determined in order to evaluate profit margins implied by premiums. 
TABLE 16

THE OPTIMAL BALANCE SHEET IN A MARKET WITH NO FRICTIONS AND NO PREFERENCE FOR FINANCIAL QUALITY.

\begin{tabular}{|c|c|c|c|c|c|}
\hline Assets & (thousands) & $\%$ & Economic Liabilities & (thousands) & $\%$ \\
\hline Invested Assets & & & Loss Reserves & & \\
\hline Cash & 144,570 & 15.0 & Motor & 293,651 & 30.5 \\
\hline Bonds & 626,470 & 65.0 & Household & 136,175 & 14.1 \\
\hline Stocks & 192,760 & 20.0 & Fire \& ISR & 39,417 & 4.1 \\
\hline \multirow[t]{14}{*}{ Total Assets } & 963,799 & & Liability & 76,958 & 8.0 \\
\hline & & & CTP & 329,468 & 34.2 \\
\hline & & & PV of Tax Liability & 0 & 0.0 \\
\hline & & & PV of Agency Cost Liability & 0 & 0.0 \\
\hline & & & Total Economic & & \\
\hline & & & Liabilities & 875,669 & 90.9 \\
\hline & & & Equity & & \\
\hline & & & Capital Subscribed & 0 & 0.0 \\
\hline & & & NPV of Profits & 62,962 & 6.5 \\
\hline & & & Default Value & 25,168 & 2.6 \\
\hline & & & Total Economic & & \\
\hline & & & Capital & 88,130 & 9.1 \\
\hline & & & Total Economic & & \\
\hline & & & Liabilities \& Capital & 963,799 & \\
\hline
\end{tabular}

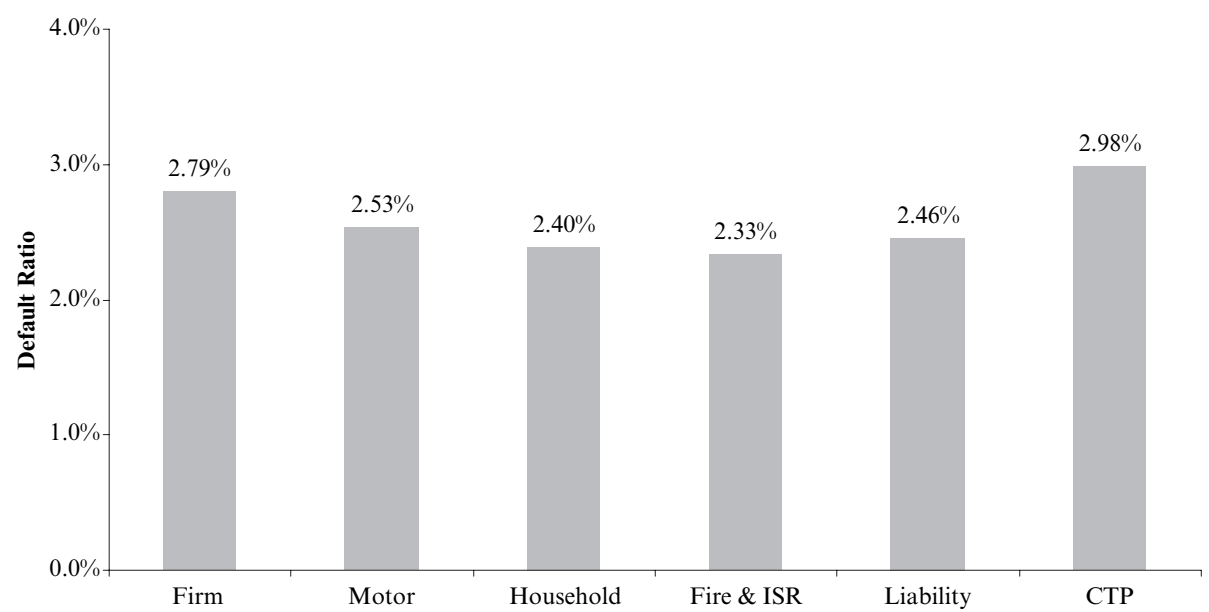

FIGURE 1: Default ratios in a frictionless market and no policyholder preferences for financial quality. 


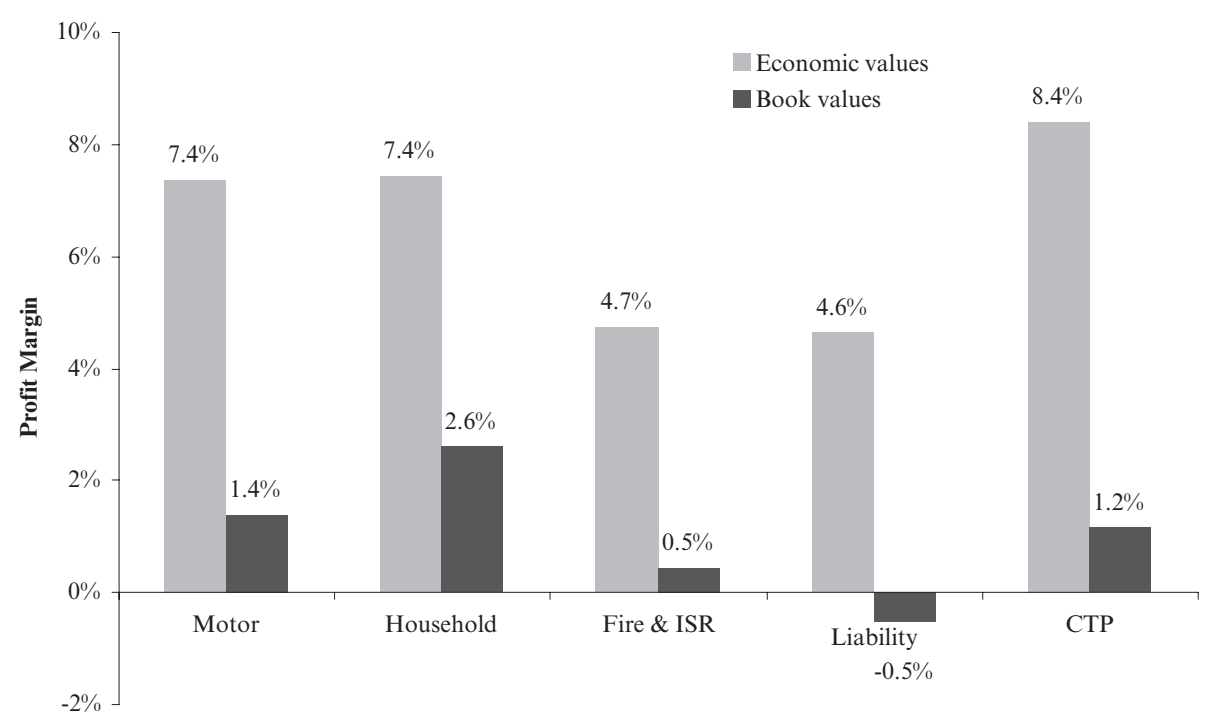

FIGURE 2: A comparison of profit margins using book and economic values.

Figure 1 gives the default option values for the insurer and for each line of business. The firm-wide default ratio is high at $2.79 \%$ of liabilities. By line of business, CTP insurance has the highest default ratio of $2.98 \%$ and it has a higher CV compared to other lines. Interestingly domestic motor insurance has a higher default ratio than liability insurance.

The optimal pricing strategy, shown in Figure 2, gives the profit margins across all lines. The economic values profit margin is defined as net premiums less the fair or economic value of liabilities adjusted for the default option value of the insurer. Profit margins ignoring default risk are used for the book values in Figure 2 and are significantly lower than economic profit margins reflecting the importance in this case of the default put option value by line.

TABLE 17

ELASTICITIES OF DEMAND BY LINE OF BUSINESS.

\begin{tabular}{lcc}
\hline \hline Lines & $\begin{array}{c}\text { Price Elasticity } \\
\text { of Demand }\end{array}$ & $\begin{array}{c}\text { Default Risk Elasticity } \\
\text { of Demand }\end{array}$ \\
\hline Motor & 11.8 & 0.37 \\
Household & 13.9 & 0.43 \\
Fire \& ISR & 22.1 & 0.66 \\
Liability & 18.0 & 0.55 \\
CTP & 7.3 & 0.24 \\
\hline \hline
\end{tabular}


The relative profit margins reflect the assumptions for the elasticities of demand for each line of business. The second column of Table 17 shows the price elasticities of demand by line of business evaluated at the optimum. Price elasticities are the percentage change in number of policies written for a $1 \%$ change in price. While the demand for insurance is price elastic across all lines of business, fire \& ISR, and liability lines are particularly sensitive to price changes with elasticities of $22.1 \%$ and $18.0 \%$ respectively. This reflects the assumption that commercial lines are more price elastic than personal and compulsory lines. The sensitivity of demand in motor and household lines have lower elasticities of $11.0 \%$ and $13.9 \%$ respectively. The demand for CTP insurance is the least elastic at $7.3 \%$. These price elasticities indicate a relatively high level of assumed competitiveness at the optimum in the model. Low elasticity lines, such as personal and compulsory, yield higher profit margins at the optimum, as demand is less sensitive to increases in premiums.

Commercial lines display higher elasticities of demand with respect to default risk when compared to personal and compulsory lines. The default risk elasticities of demand are the percentage change in the number of policies written for a $1 \%$ change in the firm-wide default ratio. Default risk elasticities evaluated at the optimum are shown in the third column of Table 17. The sensitivity of policyholder demand to default risk is highest in commercial lines. A $1 \%$ increase in the insurer's default ratio would see a reduction in policies of $0.66 \%$ and $0.55 \%$ in fire \& ISR and liability lines respectively. The demand for CTP insurance is the most inelastic with respect to default risk with an elasticity less than half that of commercial lines at $0.24 \%$. These results indicate that policyholder demand at the optimum, while elastic to changes in price, is relatively inelastic to the default ratio. This is expected as, at the optimum, the value of the default put option is relatively low at $2.79 \%$ of liabilities.

The level of profit margins generated for this assumption are reasonably consistent with, although not the same as, the tariff margins mentioned by Hill [14] and US empirical data in D'Arcy and Garven [7]. This indicates that the demand elasticities are reasonable assumptions for assessing the impact of frictional costs on profit margins. To make the model more realistic the elasticities could be calibrated to market or historical profit margins, however, this would assume that these market based profit margins were optimal. Since we are interested in the relative impact of these costs in the optimal strategy and the relative differences by line it is important to incorporate a range of elasticities in the model assumptions. Market or historical margins will be also expected to vary across insurers.

\subsection{When Financial Quality Matters}

In order to assess the impact of financial quality of the insurer we maintain the assumption of frictionless markets and consider the case where policyholders 
are assumed to care about the financial quality of the insurer, that is, for $i=$ $1, \ldots, N$ we assume

$$
\gamma_{i}=\frac{\partial q_{i, t}}{\partial d_{0}}=-1
$$

Policyholder preferences for quality result in a significant change to the insurer's optimal pricing and capital strategy. The optimal balance sheet is displayed in Table 18. Since the demand for insurance is influenced by the firm-wide risk of insolvency, the insurer must subscribe a substantial amount of capital equal to $61.0 \%$ of total assets, in order to maximize the value added from the insurance business. Since there are no frictional costs of capital, holding capital to maintain financial quality has no cost and the optimal strategy is to guarantee to meet claims in order to maximize the number of policies written and profit margins earned. It is not necessary to include frictional costs in the model in order for the insurer to have an optimal level of capitalization. This occurs when policyholders have a preference for financial quality.

The EVA maximizing pricing margins for these assumptions are given in Figure 3. For four of the five lines of business, the impact of policyholder

TABLE 18

THE OPTIMAL BALANCE SHEET IN A MARKET WITH NO FRICTIONS AND POLICYHOLDER PREFERENCES FOR FINANCIAL QUALITY

\begin{tabular}{|c|c|c|c|c|c|}
\hline Assets & (thousands) & $\%$ & Economic Liabilities & (thousands) & $\%$ \\
\hline Invested Assets & & & Loss Reserves & & \\
\hline Cash & 292,476 & 15.0 & Motor & 238,301 & 12.2 \\
\hline Bonds & $1,267,394$ & 65.0 & Household & 121,754 & 6.2 \\
\hline Stocks & 389,967 & 20.0 & Fire \& ISR & 35,012 & 1.8 \\
\hline \multirow[t]{14}{*}{ Total Assets } & $1,949,837$ & & Liability & 60,240 & 3.1 \\
\hline & & & CTP & 233,758 & 12.0 \\
\hline & & & PV of Tax Liability & 0 & 0.0 \\
\hline & & & PV of Agency Cost Liability & 0 & 0.0 \\
\hline & & & Total Economic & & \\
\hline & & & Liabilities & 689,065 & 35.3 \\
\hline & & & Equity & & \\
\hline & & & Capital Subscribed & $1,190,060$ & 61.0 \\
\hline & & & NPV of Profits & 70,712 & 3.6 \\
\hline & & & Default Value & 0 & 0.0 \\
\hline & & & Total Economic & & \\
\hline & & & Capital & $1,260,773$ & 64.7 \\
\hline & & & Total Economic & & \\
\hline & & & Liabilities \& Capital & $1,949,837$ & \\
\hline
\end{tabular}




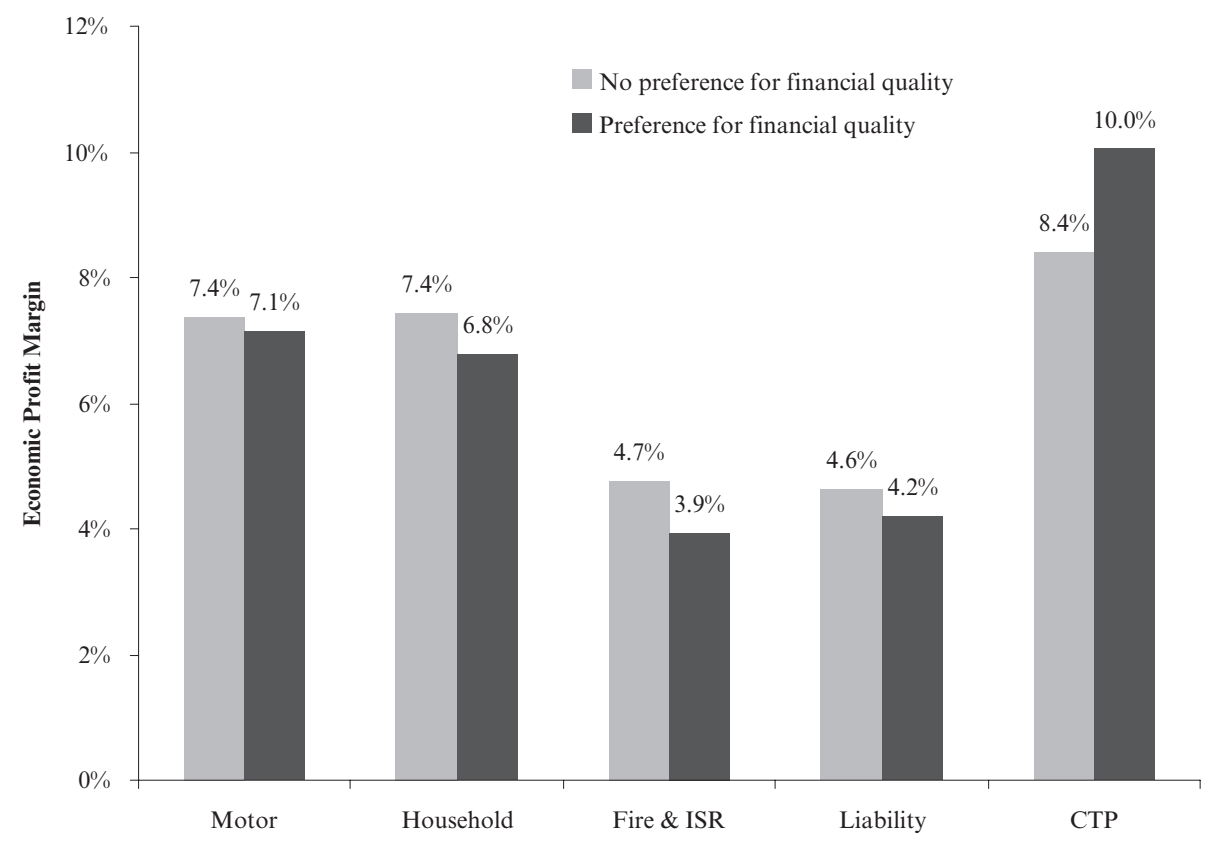

FIGURE 3: A comparison of profit margins with and without preferences for financial quality.

preferences for financial quality reduces the value maximizing profit margins. The optimal pricing strategy for CTP business is to increase the profit margins, reflecting the lower elasticity of demand for CTP insurance.

Higher default option values in competitive markets are expected to reduce premiums and hence profit margins by the value of the default option by line as in Phillips, Cummins, and Allen [25] and Sherris and van der Hoek [27]. Profit maximizing prices in imperfectly competitive markets are influenced by imperfect price elasticity as well as policyholder preferences for financial quality. For our model assumptions, profit margins for most lines of business are higher for higher values of the default put option value except for the case of CTP. Imperfect markets result in standard competitive market results no longer holding for optimal EVA capitalization and pricing strategies.

\subsection{The Impact of Frictional Costs}

\subsubsection{Corporate Tax}

We now consider the impact of corporate taxes on optimal strategies. We determine EVA maximizing strategies for a range of tax rates, from zero to $30 \%$. Other frictional costs are assumed to be zero. Increasing taxes reduces the 


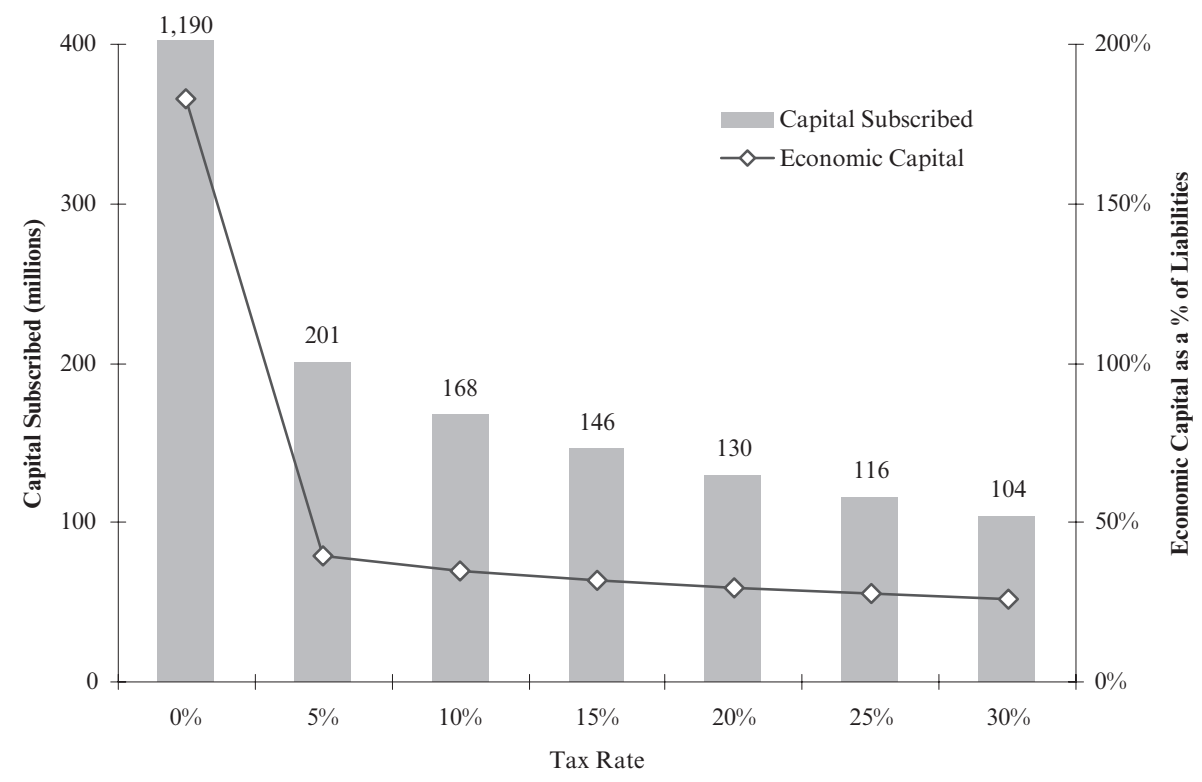

FIGURE 4: Optimal levels of subscribed capital and surplus for increasing taxes.

profitability of the insurer and the incentive for shareholders to commit capital in order to guarantee insurance claims. Figure 4 demonstrates that optimal levels of capitalization significantly reduce as taxes increase. For example, an increase in effective tax rates from $5 \%$ to $10 \%$ results in a reduction in optimal subscribed capital of $19.6 \%$. In Australia, an imputation tax credit system allows investors a credit for corporate taxes paid on dividends so that for a welldiversified investor corporate taxes are effectively zero. Capital subscribed is the amount the insurer raises initially from shareholders, denoted in Section 2.1 by $R_{0}$. Economic capital includes the value of the default put option and is the amount that assets exceed the economic value of liabilities.

TABLE 19

StANDARd AND PoOR's RATING PERFormanCE FOR ONE-YEAR DEFAUlt RATES, 1981-2003.

\begin{tabular}{lc}
\hline \hline Rating & 1 Year Default Rates \\
\hline AAA & $0.00 \%$ \\
AA & $0.01 \%$ \\
A & $0.05 \%$ \\
BBB & $0.37 \%$ \\
BB & $1.36 \%$ \\
B & $6.08 \%$ \\
CCC & $30.85 \%$ \\
\hline \hline
\end{tabular}


Figure 5 displays the impact of taxes on firm-wide insolvency risk. The reductions in optimal levels of capitalization lead to an optimal capitalization with a much lower credit quality for the insurer. A tax rate rise from 5\% to $10 \%$ causes optimal firm-wide default ratios in the model to double from $0.03 \%$ to $0.06 \%$. In order to understand the impact of taxes on default risk, results can be related to S\&P credit ratings shown in Table 19. An increase in taxes from zero to $10 \%$ lowers optimal capitalization to a level equivalent to a ratings downgrade from AAA to A.

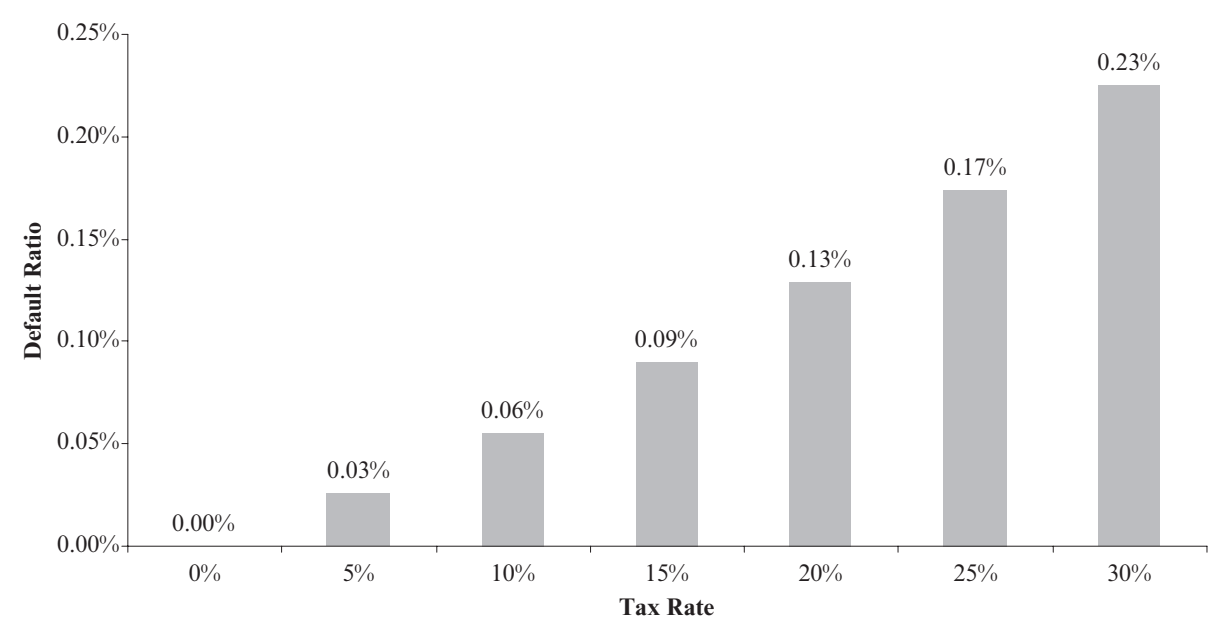

FIGURE 5: Firm-wide default ratios for increasing taxes.

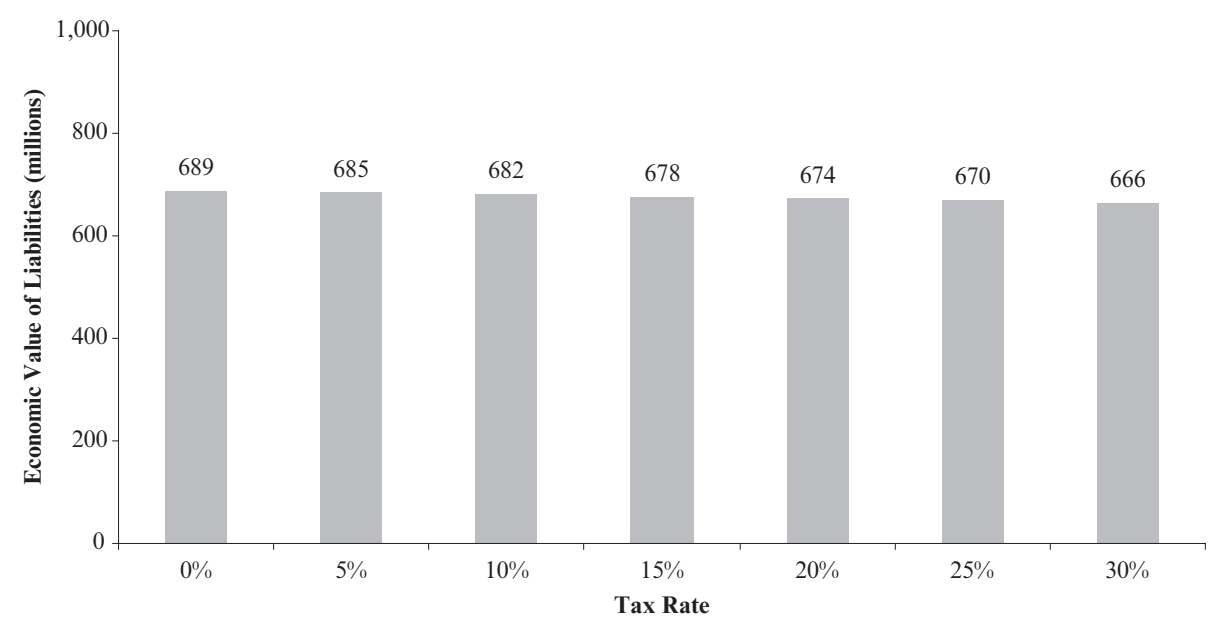

Figure 6: Economic value of liabilities for increasing taxes. 


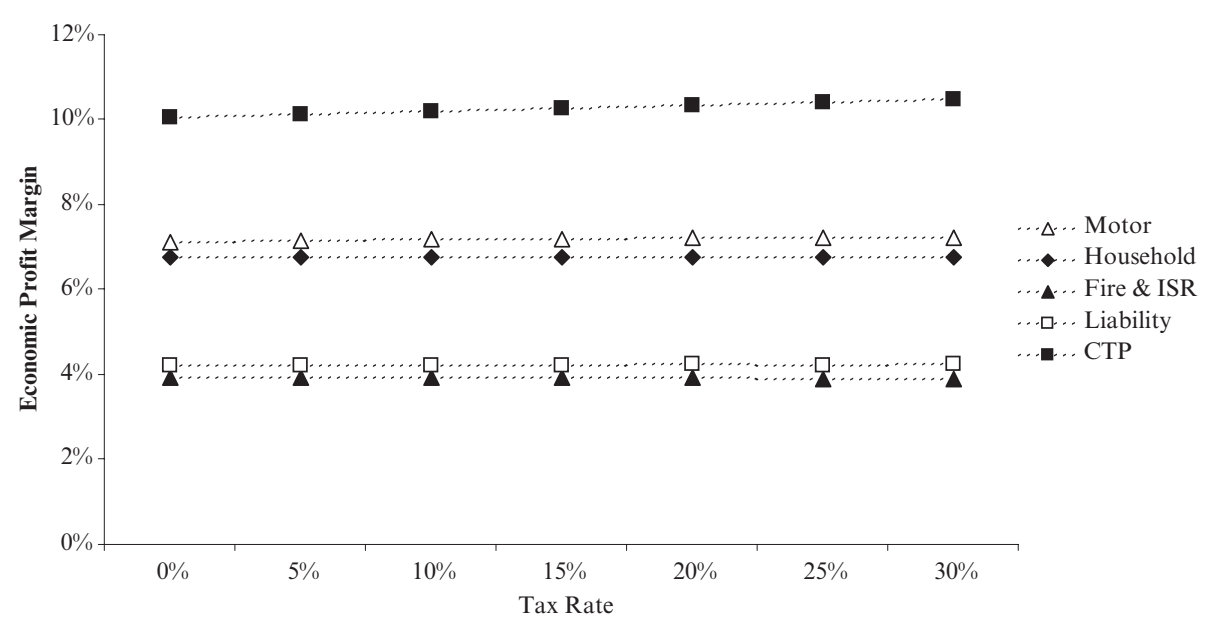

FIGURE 7: Economic profit margins for increasing taxes.

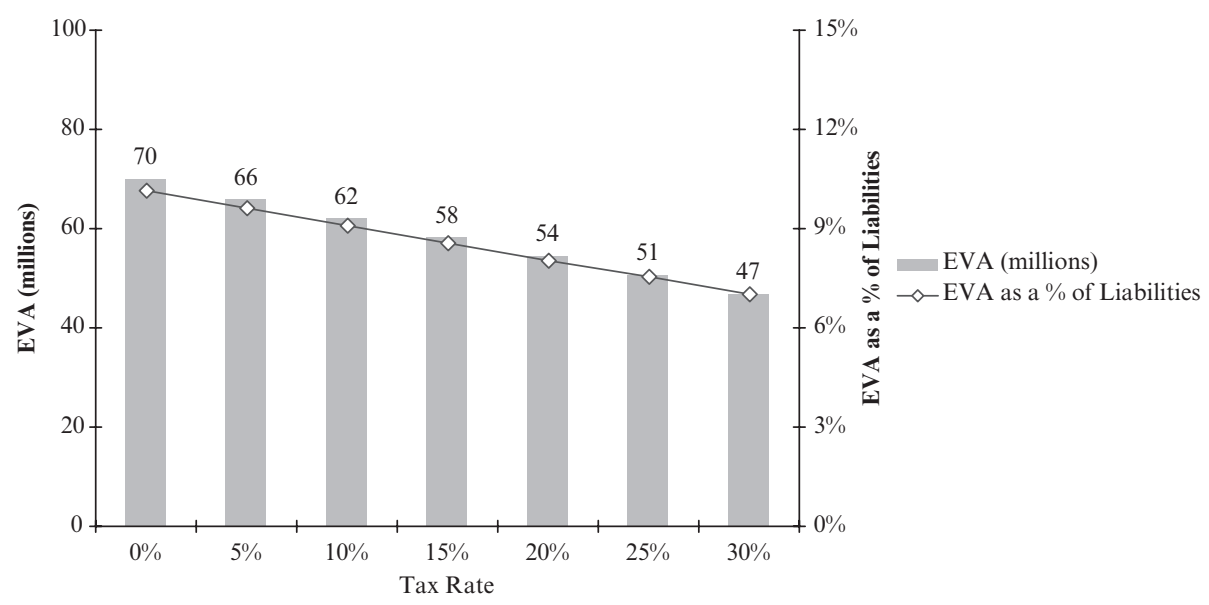

Figure 8: EVA for increasing taxes.

The results show that the increased frictional costs arising from higher taxes are borne by the shareholders of the insurer since profit margins, as shown by Figure 7, remain roughly constant as the tax rate increases. When faced with increasing taxes, the insurer's optimal risk management policy is to adjust capital structure and financial quality in order to maintain value maximizing prices. These prices allow the insurer to write similar volumes of business even as tax costs increase. For example, Figure 6 illustrates that an increase in taxes from zero to $20 \%$ only lowers the optimal economic value of liabilities by $2.16 \%$. 
Figure 8 shows that the EVA on the left hand axis consistently falls as taxes rise. Increased taxation results in a significant reduction in EVA for insurers. The initial increase in EVA as a proportion of total economic capital on the right hand axis, reflects the reduction in optimal capitalization of the firm. Increases in taxes from $5 \%$ to $10 \%$ lower shareholder value by $6 \%$.

In general, most of the burden of increased taxes fall on shareholders. Optimal pricing strategies do not recoup higher taxes. The optimal insurer response to higher taxes is to reduce capital subscribed. In the presence of taxes, active risk management policies to reduce the impact of taxes on profits will have positive impacts on capital structure and are consistent with value maximization.

\subsubsection{Agency Costs of Capital}

We now assess the impact of agency costs ranging from zero to $10 \%$, assuming all other frictional costs are zero. Swiss Re [31] suggest a level of $2 \%$ for agency costs is a reasonable assumption.

In comparison to increasing taxation, the affect of rising agency costs of capital on optimal capitalization and default risk is significantly more pronounced. Figures 9 and 10 show that optimal levels of capitalization fall as shareholder agency costs increase, and as a result, firm-wide insolvency risk deteriorates substantially. The reason is that agency costs of capital are a direct cost of raising funds externally, while taxes are levied on the profits of the insurer which are a percentage of capital. An increase in agency costs from $2 \%$ to $4 \%$ reduces the optimal level of subscribed capital by $45.3 \%$. This is a significant reduction which causes default risk to more than double from $0.20 \%$ to $0.41 \%$.

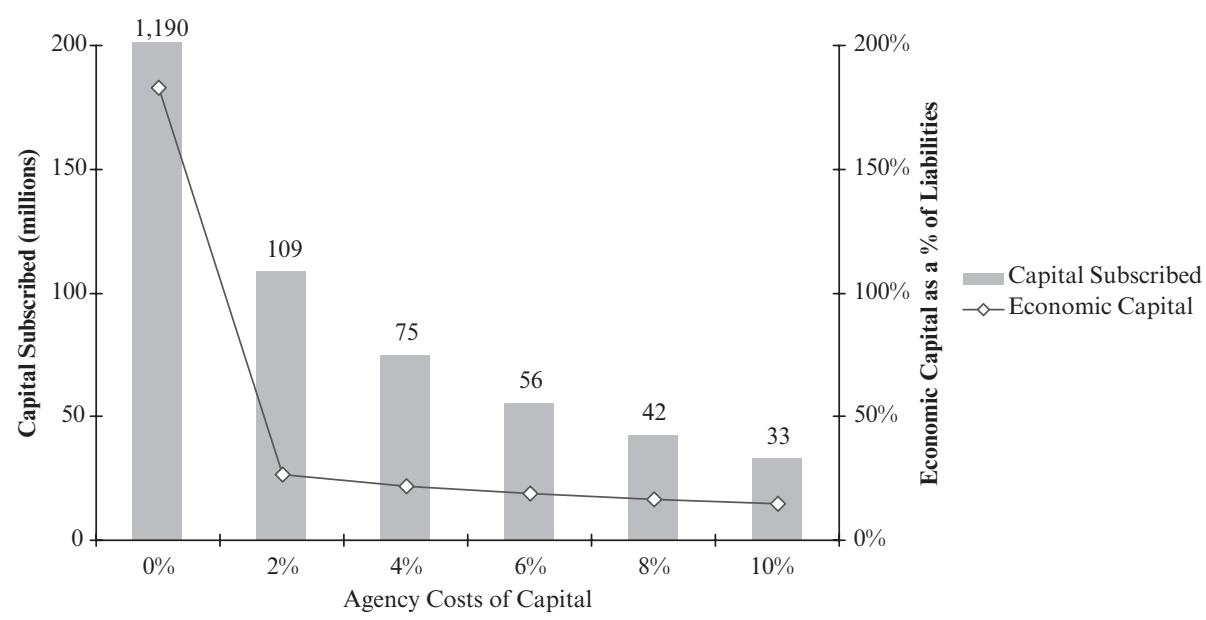

Figure 9: Optimal capital subscribed and surplus for increasing agency costs of capital. 


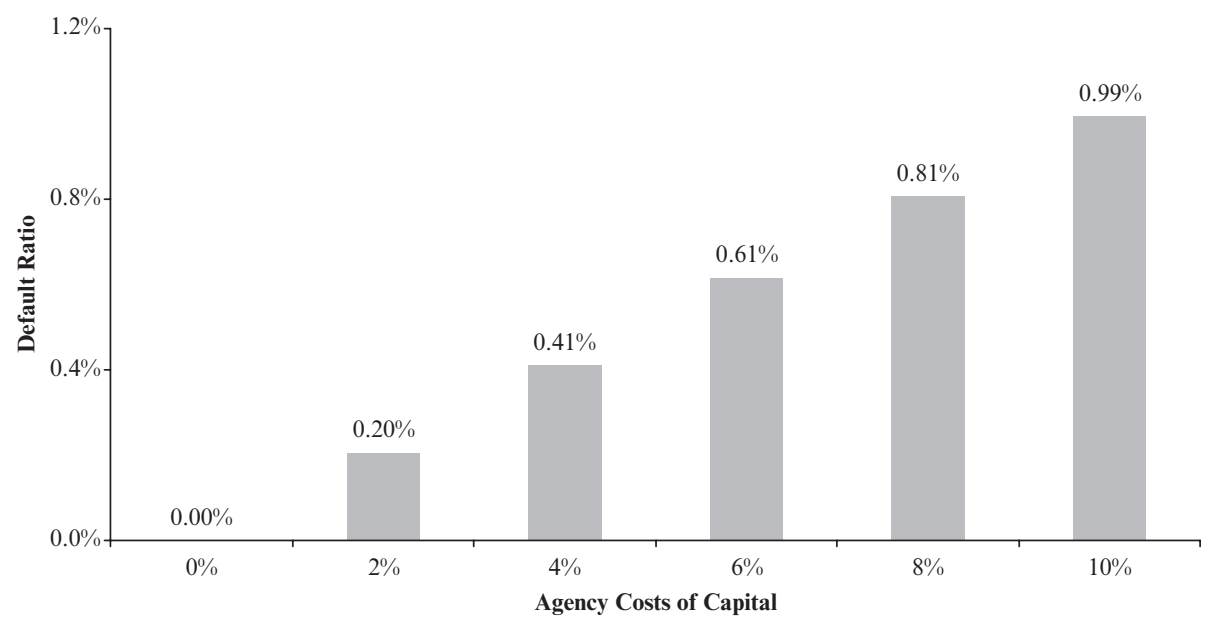

Figure 10: Default ratios for increasing agency costs of capital.

For every line of business except CTP, the optimal profit margins remain relatively constant as frictions increase as shown in Figure 11. This result reflects the assumption of a lower price elasticity of demand in compulsory lines. We conclude that the insurer's capital decision is the active arm of risk management and allows optimal prices to be maintained despite increasing agency costs of capital. When compared with the impact of increasing taxes, agency costs of capital have a greater impact on the firm's underwriting strategies. Figure 12 indicates that for an increase in agency costs from zero to $2 \%$,

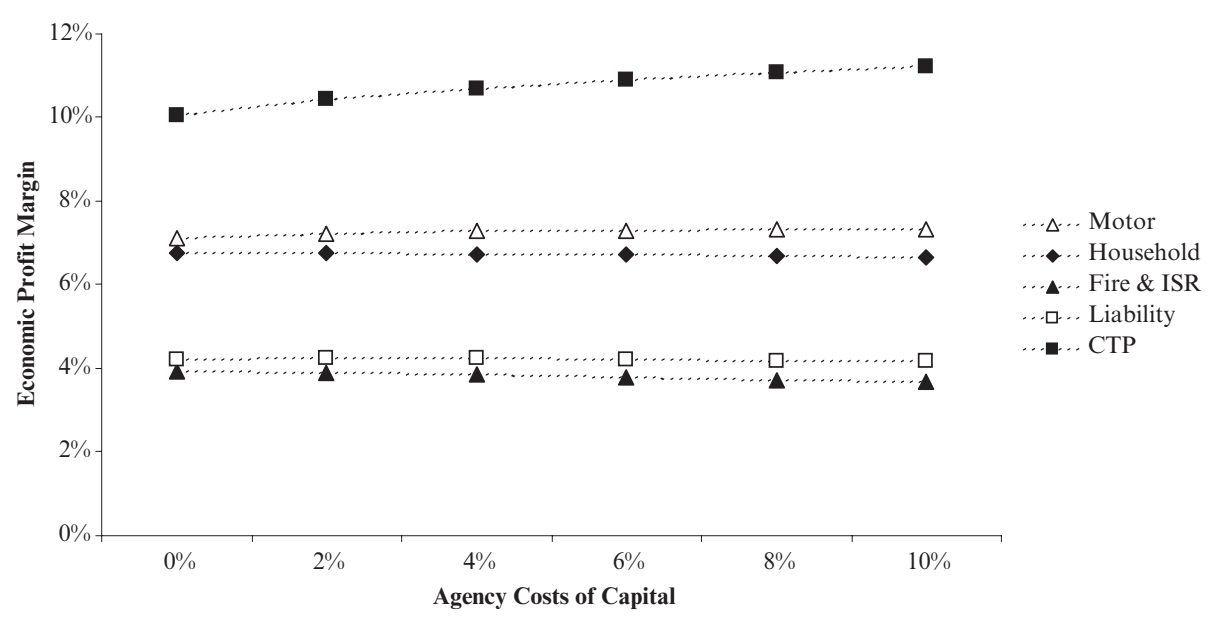

FIGURE 11: Economic profit margins for increasing agency costs of capital. 


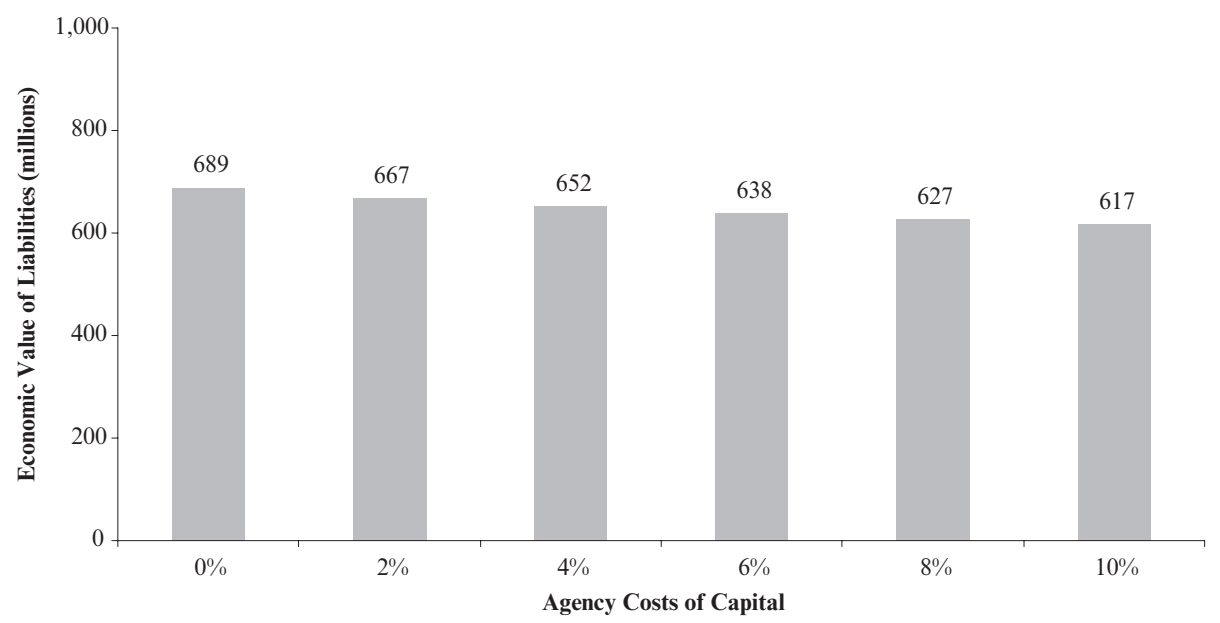

FIGURE 12: Economic value of liabilities for increasing agency costs of capital.

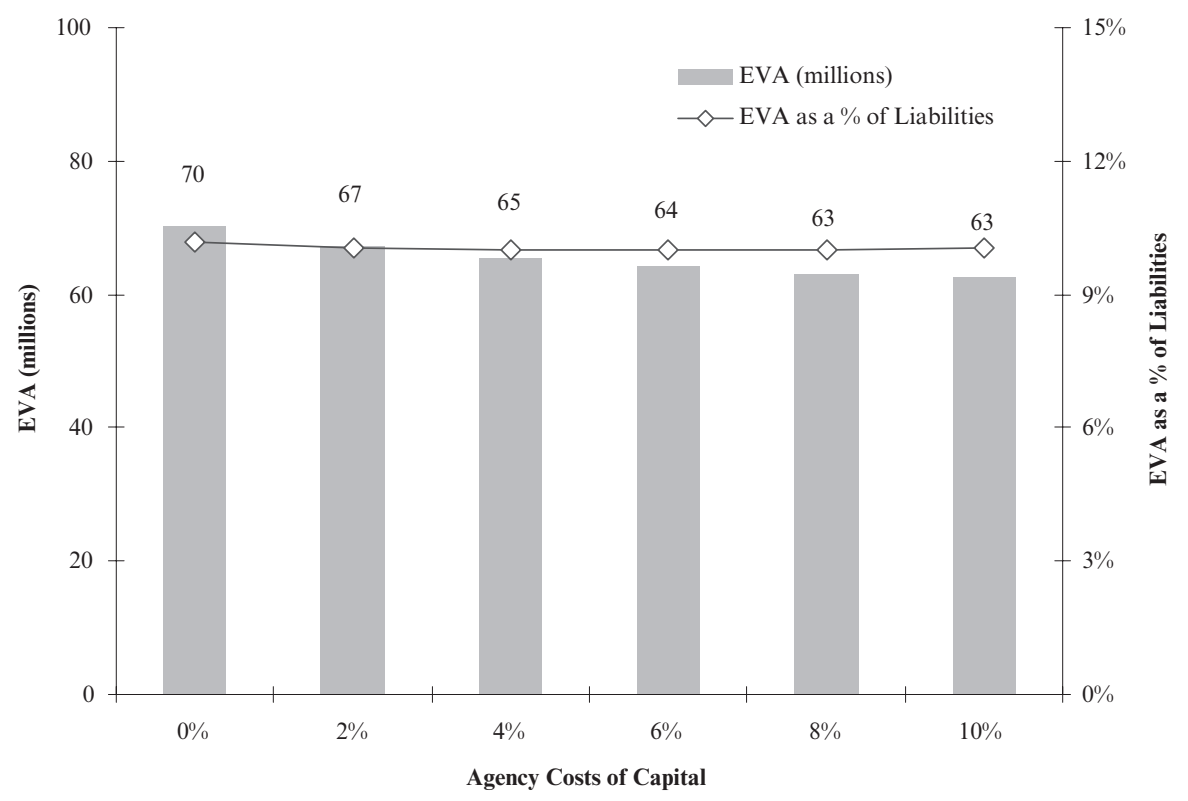

FIGURE 13: EVA for increasing agency costs of capital.

the optimal economic value of liabilities falls by $3.3 \%$ in response to the deterioration in insurer credit quality.

Shareholder value is also eroded by agency costs of capital, however, the impact on profitability is not as pronounced as in the case of taxes. While agency costs of capital have a substantial impact on capital structure, Figure 13 reveals 
that the impact on shareholder EVA is not as pronounced as for taxes. In fact, EVA as a proportion of total liabilities remains roughly constant for increasing agency costs.

\subsubsection{Bankruptcy Costs}

Costs of financial distress are studied in Altman [1]. In our model, bankruptcy costs are assumed to increase the sensitivity of insurance demand to default risk since

$$
\frac{\partial q_{i, t}}{\partial d_{0}}=-(1+f) .
$$

We now assume that the model insurer faces a $2 \%$ agency cost of capital and shareholders are able to offset taxes with imputation tax credits, so the effect of corporate taxes is zero. We determine the insurer's optimal strategy as bankruptcy costs increase over the range zero to $50 \%$.

In response to increasing bankruptcy costs, it is optimal for the insurer to increase capitalization in order to improve the financial quality of the firm. Figures 14 and 15 indicate that an increase in bankruptcy costs from zero to $10 \%$ raises optimal levels of capitalization by $9.2 \%$ and lowers default risk from $0.20 \%$ to $0.13 \%$. The bankruptcy costs are borne by the policyholder in the event of the insurer defaulting on claims. These are the direct costs of

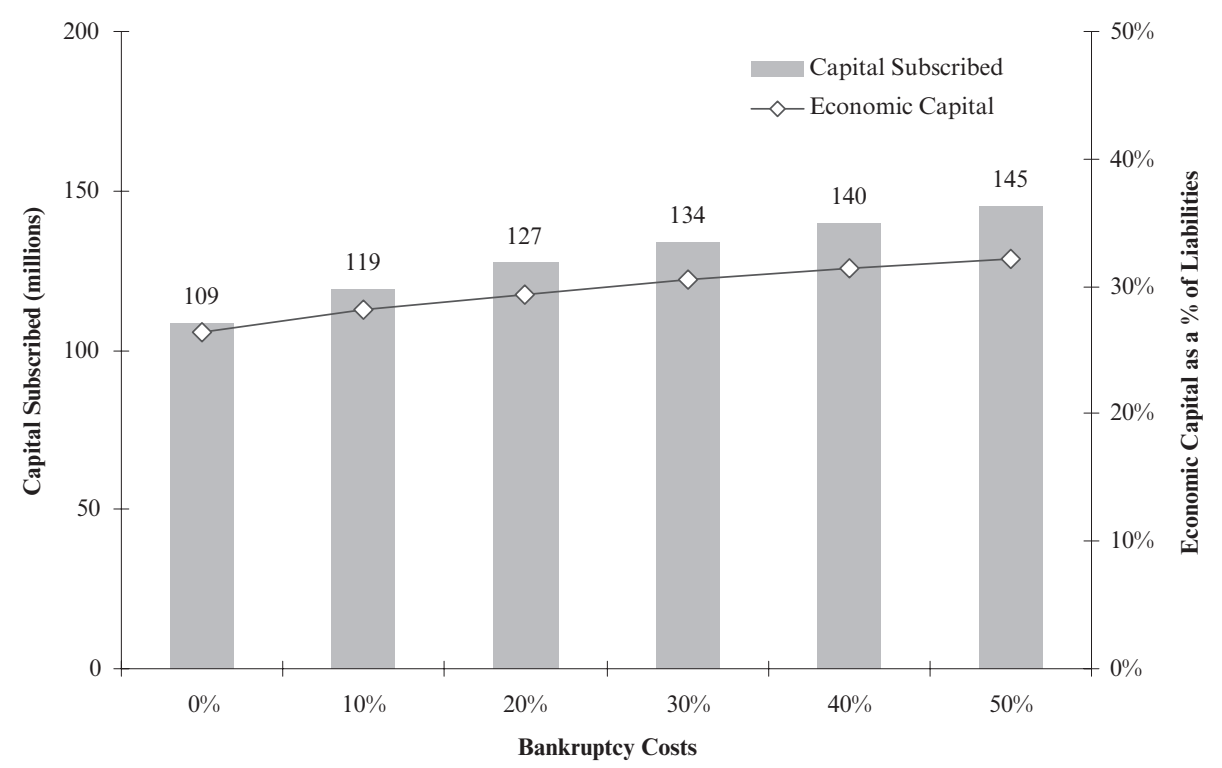

Figure 14: Optimal capital subscribed and surplus for increasing bankruptcy costs. 


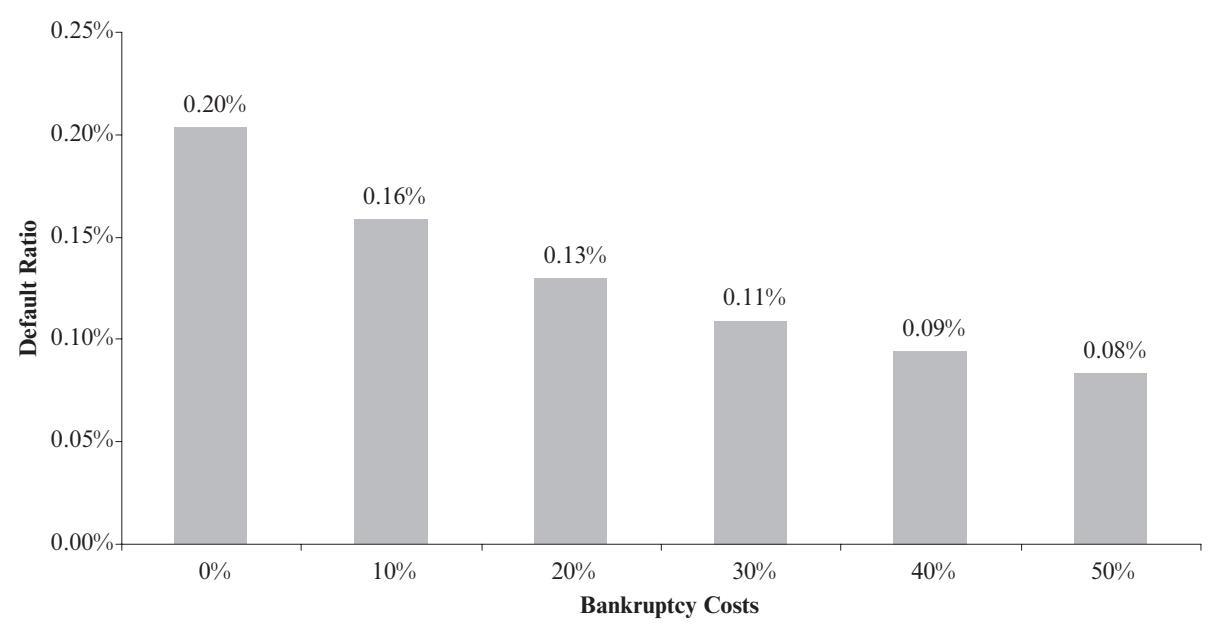

FIGURE 15: Default ratios for increasing bankruptcy costs.

bankruptcy, as defined by Altman [1]. For the insurer, these direct costs of bankruptcy produce a trade-off between the benefits of maintaining financial quality and the frictional costs of holding capital. For an insurer facing agency costs of capital of $2 \%$ and increasing bankruptcy costs, the benefits of improving financial quality outweigh the cost of holding additional capital.

In the presence of costs of financial distress, the insurer must improve financial quality in order to write the same amount of business when these frictions do not exist. Despite the improved credit quality of the insurer, Figure 16 indicates that the higher financial quality does not result in the insurer

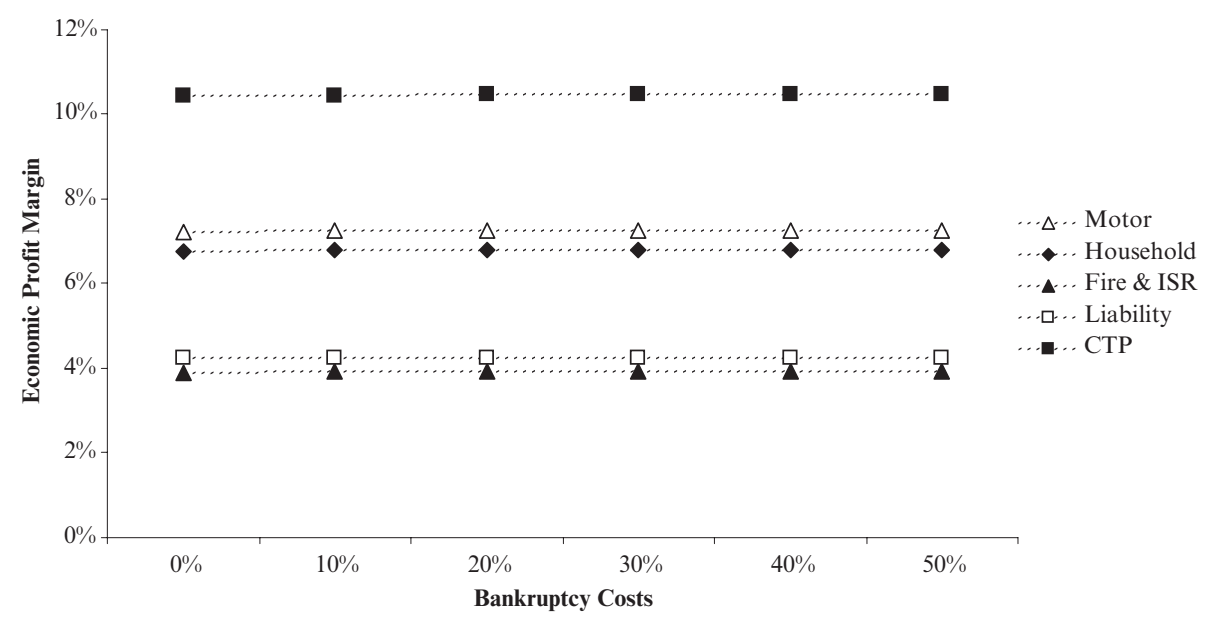

FIGURE 16: Economic profit margins for increasing bankruptcy costs. 


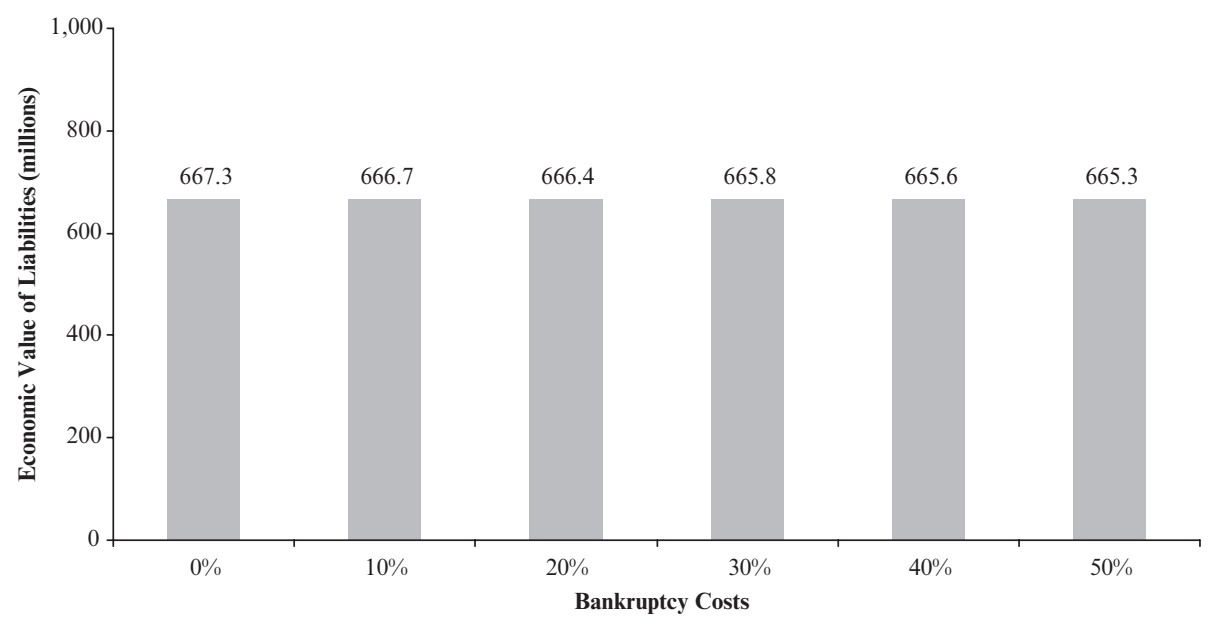

FIGURE 17: Economic value of liabilities for increasing bankruptcy costs.

commanding a higher price from policyholders. The shareholders actually bear most of the costs of bankruptcy. Figure 17 reveals that at these prices, levels of business underwritten remain roughly constant despite the reduction in default risk since the policyholder's perception of firm-wide default risk is magnified by the costs of bankruptcy.

With regard to shareholder value, Figure 18 shows that the impact on EVA is not significant. This contrasts with the results from increasing taxes and is similar to the impact of agency costs of capital since the costs of financial distress affect policyholder demand for insurance. It is optimal for the firm to

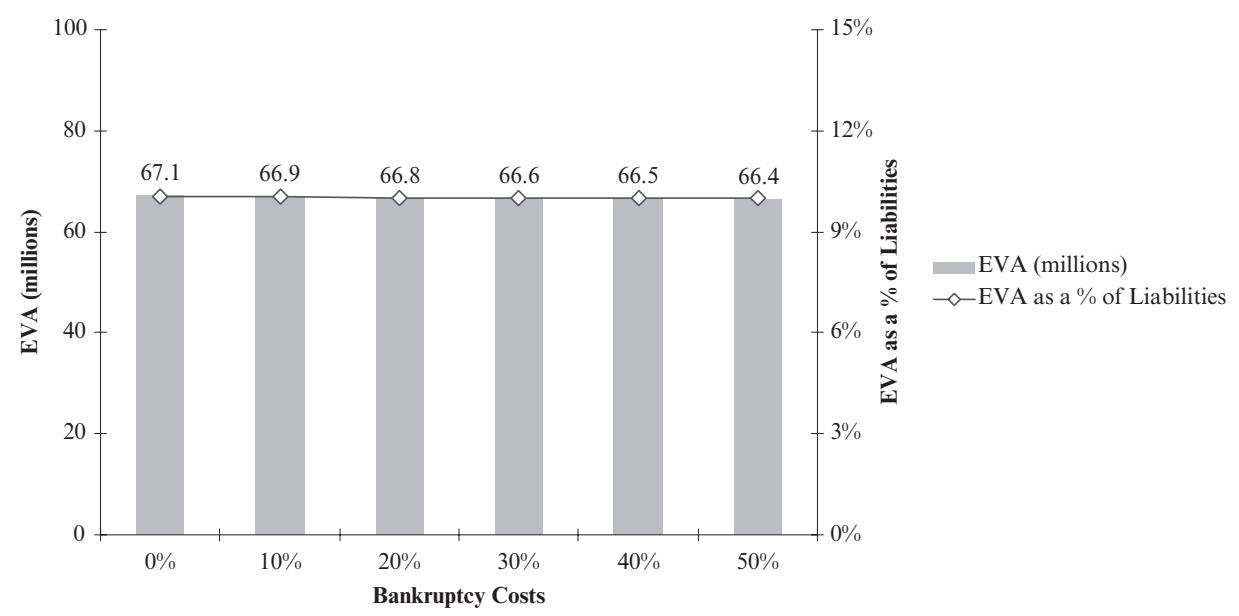

FIGURE 18: EVA for increasing bankruptcy costs. 
increase capitalization in order to improve financial quality and continue to write similar amounts of business.

\subsection{Asset and Liability Correlation}

Froot et al. [12] and Froot and Stein [11] show that when firms face costly external financing it is optimal to hedge all tradeable risks in capital markets. This has implications for insurer asset liability management. So far we have assumed a zero correlation between assets and liabilities. We now relax this assumption since hedging should induce a positive correlation between assets and liabilities. We continue to assume that the insurer incurs agency costs of capital of $2 \%$, bankruptcy costs of $25 \%$, and shareholders are able to offset taxes with imputation tax credits such that the effect of corporate taxes is zero. As expected the results demonstrate how asset-liability management is very important to value maximization of an insurer and can significantly reduce the risk of insolvency and hence add value through policyholder demand for financial quality.

Figures 19 and 20 demonstrate that in the presence of frictional costs higher correlations between assets and liabilities significantly reduce optimal levels of capital. For example, by increasing the assumed correlation between the assets and liabilities from -0.2 to 0.2 , the insurer can reduce capital levels by $38.5 \%$. In this example, capital is costly to hold and lower capitalization at the optimum leads to savings of $\$ 0.84$ million on capital costs.

Asset-liability management improves financial quality even with lower optimal levels of capital. Matching assets with liabilities increases their correlation and reduces the volatility of the insurer's surplus, resulting in lower default risk. For example, the difference between two asset mixes with correlations of -0.2 and 0.2 is a reduction in default risk of $0.3 \%$.

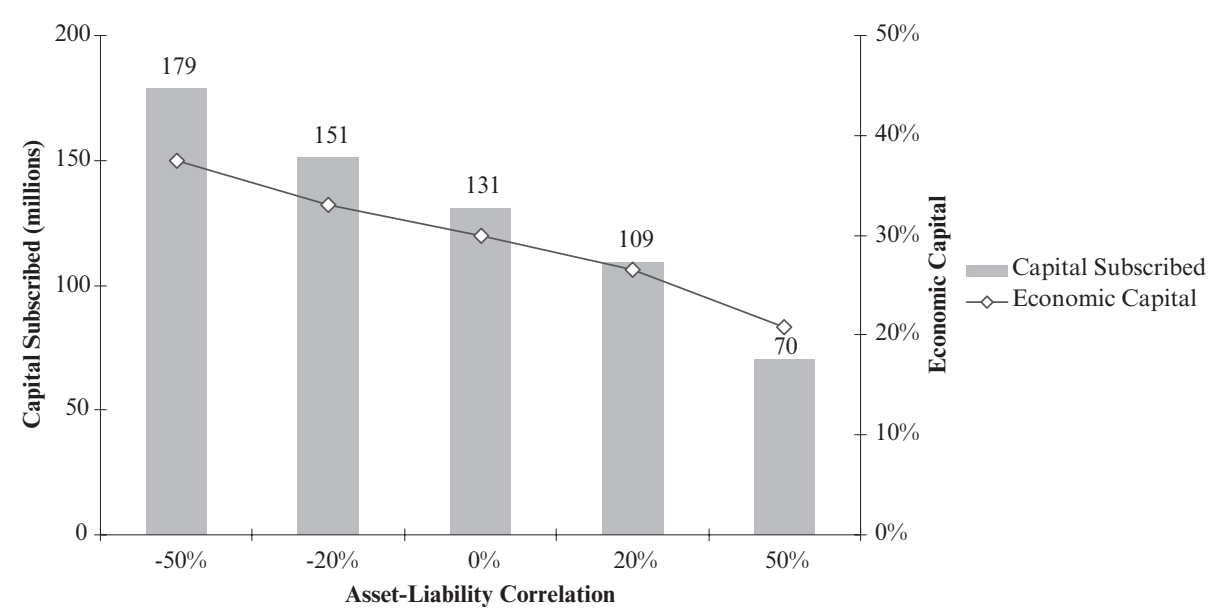

FIGURE 19: Optimal subscribed capital and surplus for different asset-liability correlations. 


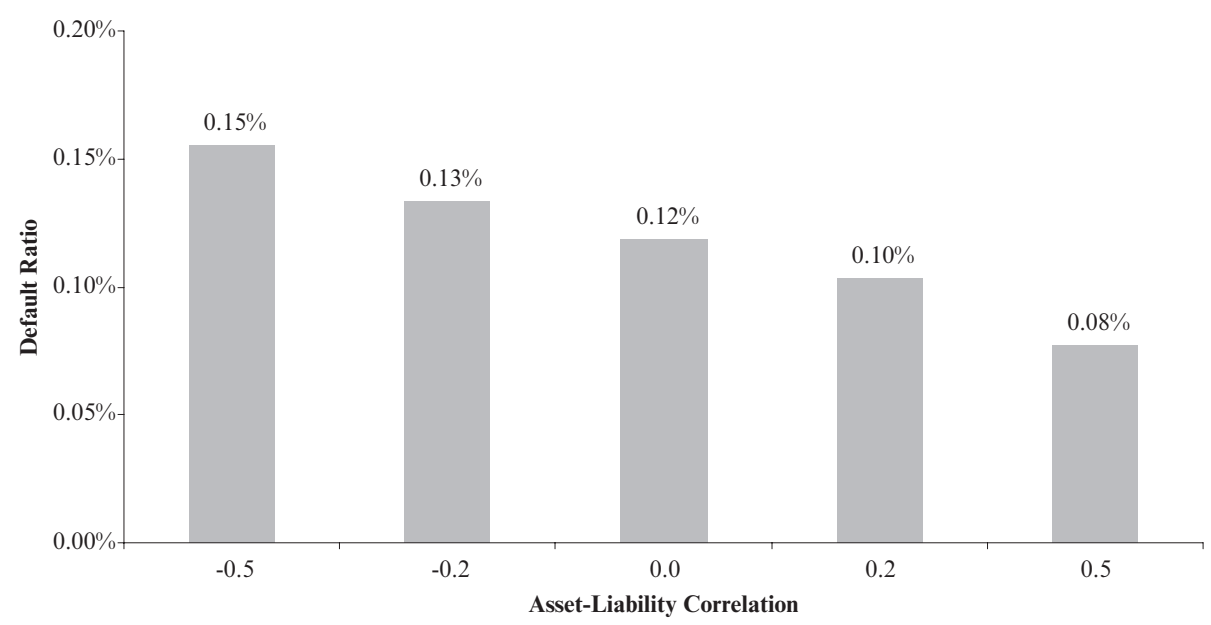

FigurE 20: Firm-wide default ratios for different asset-liability correlations.

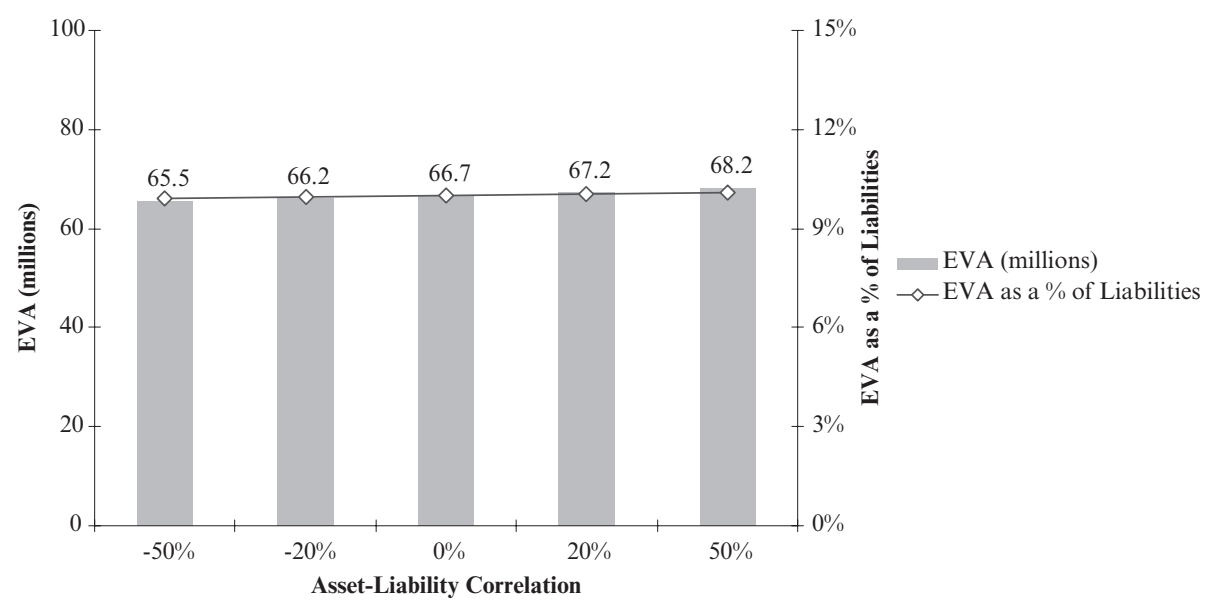

FIGURE 21: EVA for different asset-liability correlations.

Overall, the impact of this increase in asset-liability correlation lowers capital costs and improves financial quality, leading to an increase in underwriting volumes and an increase in EVA.

\subsection{Policyholder Demand and the Risk of Default}

So far we have assumed that policyholders have a constant sensitivity to default risk across all lines of business, such that $\gamma_{i}=-1$ for $i=1, \ldots, N$. We now 
consider a range of values for $\gamma_{i}$ between -0.75 and -2.00 , while maintaining the assumption that the effect of taxation on shareholders is zero, agency costs of capital are $2 \%$, and bankruptcy costs are $25 \%$.

As shown in Figures 22 and 23, the sensitivity of policyholder demand to firm-wide default risk has a significant impact on the insurer's optimal capital strategy. As policyholders become twice as sensitive to the insurer's financial quality, with $\gamma_{i}$ decreasing from -1.00 to -2.00 , the optimal level of capital increases significantly by $34.6 \%$, which lowers firm-wide default risk from $0.12 \%$ to $0.04 \%$.

The optimal response to the increased sensitivity of demand to default risk is to increase capitalization and improve financial quality. As shown in Figures 24 and 25, the insurer is able to maintain value-adding prices and write a similar amount of business. A decrease in $\gamma_{i}$ from -1.00 to -2.00 only results in a $0.45 \%$ reduction in the economic value of liabilities written. As the insurer is able to maintain its pricing strategy, despite an increasing sensitivity to default risk, the firm's EVA does reduce slightly by $1.3 \%$ as shown in Figure 26.

\subsection{Implications of Results for Enterprise Risk Management}

Frictional costs provide incentives for risk management. We show that both capital and pricing strategies are important to an insurer's optimal risk management policy, and in particular, that frictional costs influence the optimal capital structure for an insurer. Holding too high a level of capital results in higher taxes and agency costs. Holding too low a level of capital increases the risk of bankruptcy and reduces the profits from insurance margins when policyholders care about financial quality. We have shown that in the presence of frictional costs, any risk management strategy that reduces these costs will enhance enterprise

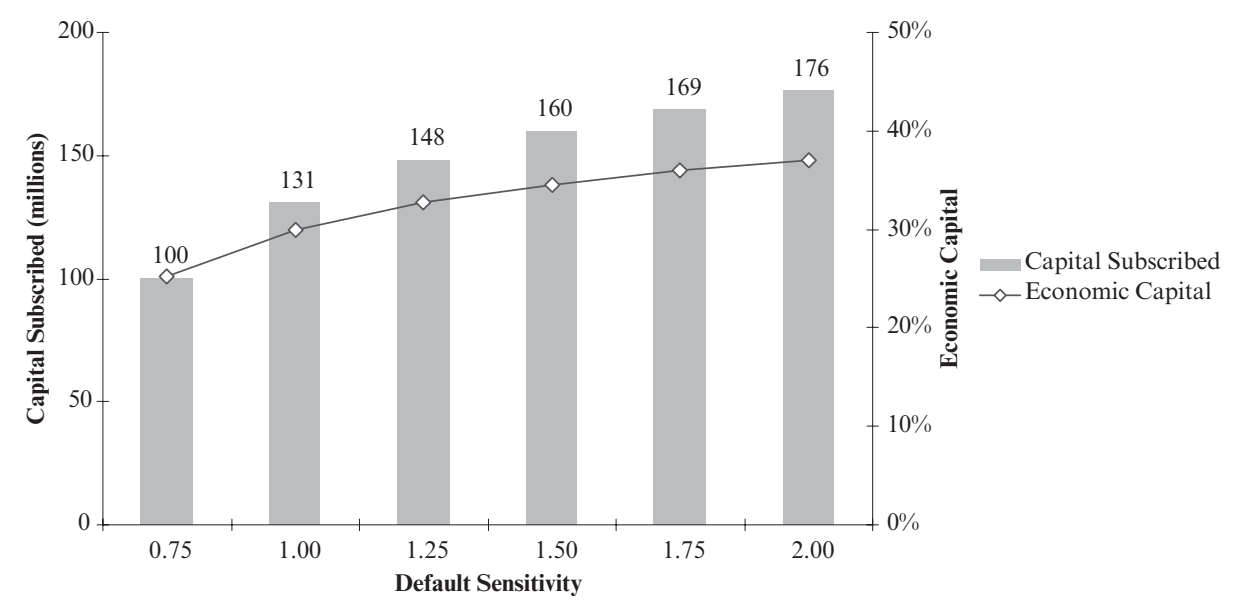

FIGURE 22: Optimal capital subscribed and surplus for increasing policyholder default sensitivity. 


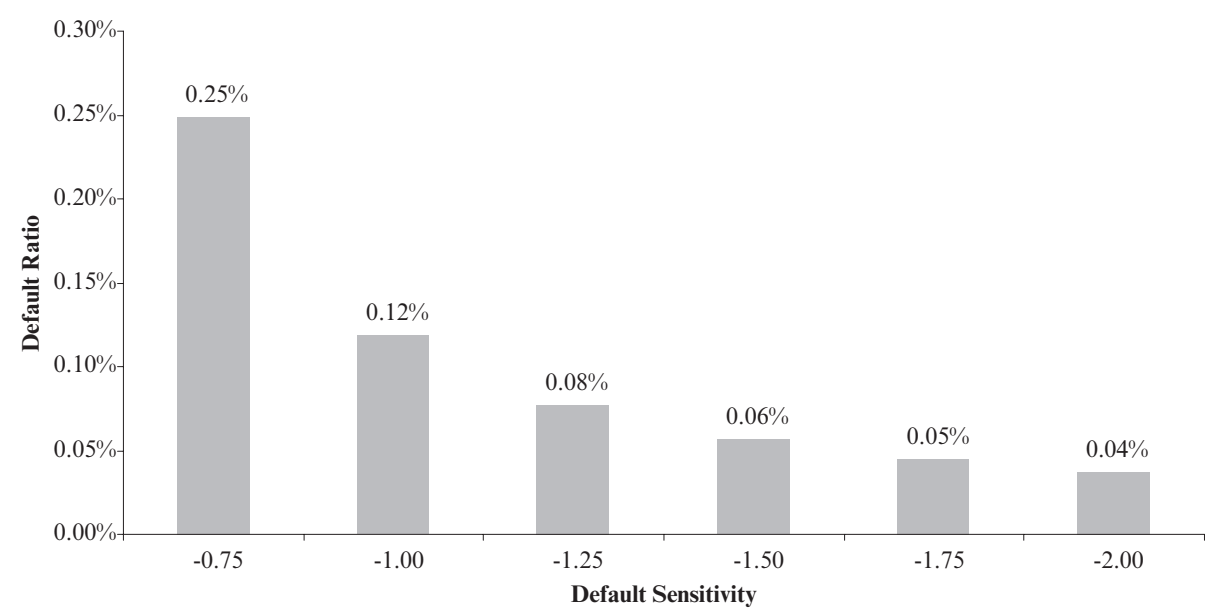

FIGURE 23: Default ratios for increasing policyholder default sensitivity.

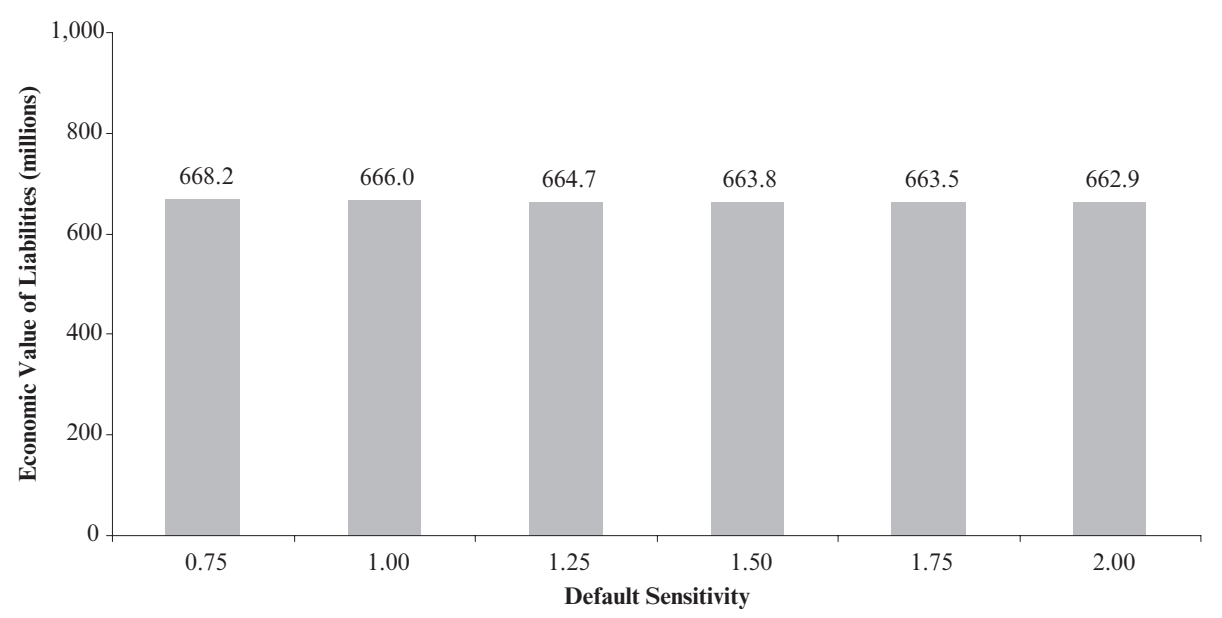

FIGURE 24: Economic value of liabilities for increasing policyholder default sensitivity.

value. In a situation of imperfect insurance markets where policyholders care about the risk of insolvency and capital is costly to hold, risk management strategies need to focus on optimal capitalization. Pricing margins by line of business are determined by policyholder preferences for quality and price elasticity and are much less influenced by frictional costs.

In the case of taxes and agency costs of capital, as these frictions increase, maintaining financial quality becomes expensive and the insurer's optimal risk management strategy is to reduce capitalization. For increased bankruptcy 


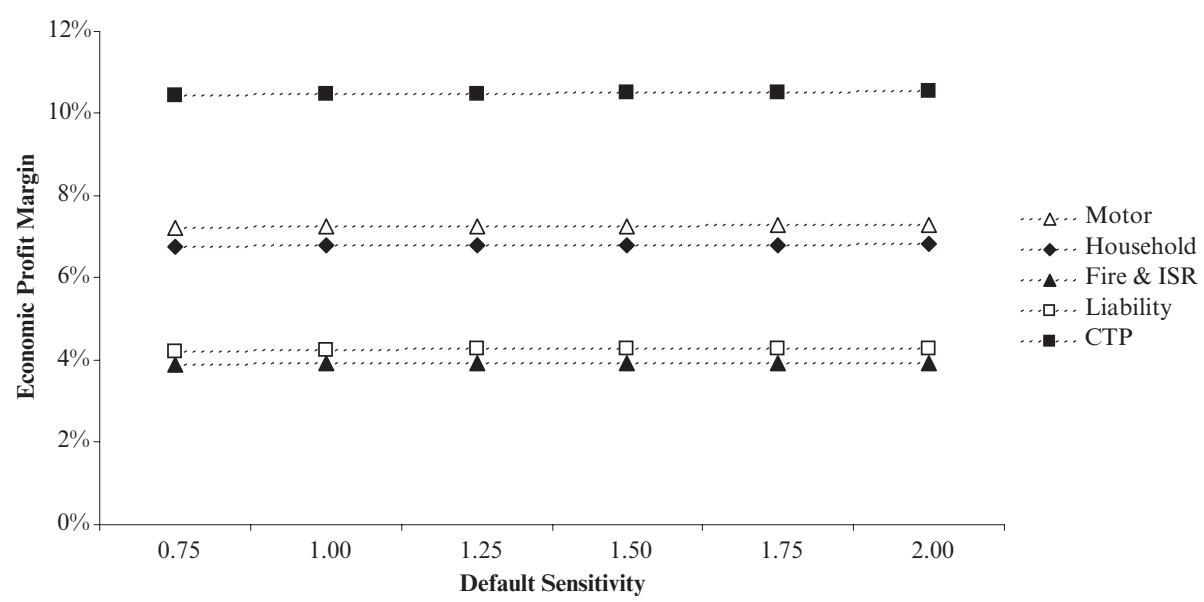

FIGURE 25: Economic profit margins for increasing policyholder default sensitivity.

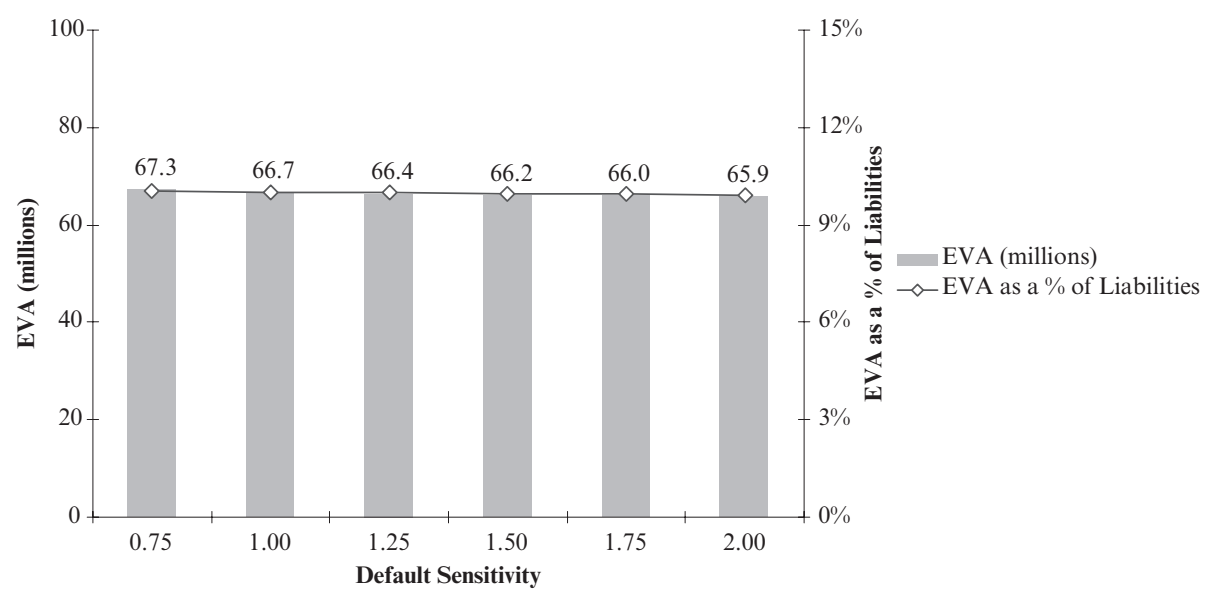

FIGURE 26: EVA for increasing policyholder default sensitivity.

costs, the optimal response is to increase subscribed capital in order to maintain the insurer's ability to write business in insurance product markets. Capital structure is important in managing the trade-off between the costs of holding capital and the benefits of maintaining financial quality. Agency costs of capital, like taxes, increase the costs of maintaining financial quality. Agency costs of capital directly affect the insurer's cost of raising capital, and as a result, the impact of these frictions on risk management policies is more pronounced than taxes. 
Bankruptcy costs result in the insurer raising additional capital in order to improve the financial quality of the firm, in order to maintain value maximizing prices and write optimal levels of business. The optimal response of capital strategies to agency costs and bankruptcy costs attenuate the loss in enterprise value, with EVA remaining at an approximately constant percentage of liabilities for increases in these frictional costs.

Matching assets and liabilities is an important part of effective risk management. We show, for our model assumptions, that small increases in the asset-liability correlation significantly reduce the insurer's optimal capitalization and improve financial quality. By increasing the correlation between assets and liabilities, the insurer can lower costs from holding capital and increase enterprise value.

For our model assumptions, shareholders bear the costs of capital in a market where policyholder demand for insurance is inelastic. We show that the optimal response of pricing strategies to increasing frictional costs is generally to leave economic profit margins at approximately constant value maximizing levels. For the insurer, capital management is then the active arm of risk management and, at the optimum, must be designed to reduce the frictional costs borne by the insurer. The price elasticity of policyholder demand will make it sub-optimal to pass these frictional costs to policyholders through higher insurance premium profit margins. Doing this will reduce shareholder value by reducing the value of profit margins from reduced business volumes.

For our model assumptions, profit margins are not significantly lower for insurers with lower financial quality in imperfect product markets. Insurers with a higher risk of default will have lower capitalization and will write lower volumes of business if they charge the same prices as insurers with lower default risk.

\section{Conclusions}

There is an increasing awareness of the role of economic capital, not only as a risk management tool, but also in its capacity to measure value and influence financial decision-making. Most of the recent focus has been on risk based capital requirements with limited study of enterprise value maximizing capital strategies. For insurers in particular, the presence of high frictional costs creates a trade-off between the costs of holding capital and the benefits of maintaining financial quality. We examine this trade-off and provide guidance for the determination of economic capital allowing for imperfect markets.

This paper developed a single-period economic model of a multi-line insurer in an imperfect market with frictional costs of capital, imperfectly elastic demand for insurance, and policyholder preferences for financial quality.

The model was calibrated to be representative of a large diversified general insurer and the impact of frictional costs on risk management and capital was quantified. 
We find for our model assumptions that frictional costs do provide a strong rationale for risk management, as quantified by optimal capital, and consistent with enterprise value maximization. Holding optimal levels of capital will reduce frictional costs from writing insurance business and allows profit maximizing sales of policies with policyholder preferences for financial quality. Frictional costs are not required in order for the insurer to have an optimal capitalization. Policyholder preferences for financial quality alone also result in an optimal insurer capitalization.

A range of assumptions concerning frictional costs were examined to assess the impact on the results. Assumptions used were as realistic as possible, however, there is a lack of information about price elasticity by line of business and profits margins in the general insurance industry. Assumptions for policyholder demand were used that produced price margins that were generally in line with historical data and that were consistent with a relatively competitive market. Further research on price elasticity would benefit studies of the optimal capital structure of insurers.

We find that optimal price margins are not highly sensitive to frictional costs of capital. In imperfect insurance markets we find that pricing margins are mainly determined by price elasticities and policyholder preferences for financial quality. We also demonstrate that the value of the default option value is an important measure of the capital adequacy and solvency of an insurer and impacts on the capitalization of the insurer. However, this default option value by line does not fully reflect in the profit margins of insurance premiums since the enterprise value maximizing pricing margins are relatively insensitive to this value. We also find that pricing margins are not significantly impacted by higher levels of frictional costs since shareholders actually bear most of these costs. We have considered both capital, which reflects the impact of frictional costs, and value added which reflects insurance pricing margins.

Risk based capital and economic capital models only focus on the capital decision. Enterprise risk management must focus more broadly than economic capital if it is to add value to the financial management of an insurer. We have aimed to provide a basis for broadening the focus of enterprise risk management by demonstrating the benefits of considering enterprise value adding capital and pricing strategies in a consistent model framework. We have also formally incorporated optimal decision making into a model with market frictions and imperfect demand elasticity. In a companion paper we study capital allocation and pricing using the EVA approach that is presented and analyzed in this paper.

\section{REFERENCES}

[1] Altman, E.I. (1984) 'A Further Empirical Investigation of the Bankruptcy Cost Question.' Journal of Finance 39, 1067-1089.

[2] Cochrane, J.H. (2005) Asset Pricing. Princeton University Press.

[3] Culp, C.L. (2001) The Risk Management Process. John Wiley and Sons, New York. 
[4] Cummins, J.D., Lin, Y., and Phillips, R.D. (2006) 'Capital Allocation and the Pricing of Financially Intermediated Risks: An Empirical Investigation.' Wharton Financial Institutions Center 06-13.

[5] Cummins, J.D. and Phillips, R.D. (2005) 'Estimating the Cost of Equity Capital for Property-Liability Insurers.' Journal of Risk and Insurance, 72(3), 441-478.

[6] Cummins, J.D. and Danzon, P.M. (1997) 'Price, Financial Quality, and Capital Flows in Insurance Markets.' Journal of Financial Intermediation 6, 3-38.

[7] D'Arcy, S.P. and Garven, J.R. (1990) 'Property-Liability Insurance Pricing Models: An Empirical Evaluation.' Journal of Risk and Insurance 57, 391-430.

[8] D'Arcy, S.P. and GorvetT, R.W. (1998) 'A Comparison of Property/Casualty Insurance Financial Pricing Models.' Proceedings of the Casualty Actuarial Society, LXXXV; Part 1, 162, 1-88.

[9] Doherty, N.A. and Garven, J.R. (1986) 'Price Regulation in Property-Liability Insurance: A Contingent-Claims Approach.' Journal of Finance 41, 1031-1050.

[10] Frenkel, M., Hommel, U. and Rudolf, M. (eds.) (2005) Risk Management: Challenge and Opportunity. Springer, Berlin-Heidelberg.

[11] Froot, K.A. and Stein, J.C. (1998) 'Risk Management, Capital Budgeting, and Capital Structure Policy for Financial Institutions: An Integrated Approach.' Journal of Financial Economics 47, 55-82.

[12] Froot, K.A., Scharfatein, D.S. and Stein, J.C. (1993) 'Risk Management: Coordinating Corporate Investment and Financing Policies.' Journal of Finance 48, 1629-1658.

[13] Hancock, J., Huber, P. and Koch, P. (2001) 'The Economics of Insurance: How Insurers Create Value for Shareholders.' Swiss Re Technical Publishing 2nd Edition.

[14] HiLl, R. (1979) 'Profit Regulation in Property-Liability Insurance.' Bell Journal of Economics 10, 172-191.

[15] Hitchcox, A.N., Hinder, I.A., Kaufman, A.M., Maynard, T.J., Smith, A.D. and White, M.G. (2006) 'Assessment of Target Capital for General Insurance Firms.' Paper presented to the Institute of Actuaries 27 November 2006.

[16] Lewis, R.M. and Torczon, V. (2000) 'Pattern Search Methods for Linearly Constrained Minimization.' SIAM Journal on Optimization 10, 917-941.

[17] LI, L. (2002) 'Macroeconomic Factors and the Correlation of Stock and Bond Returns.' Yale International Center for Finance Working Paper.

[18] MacMinn, R.D. (2005) The Fisher Model and Financial Markets. World Scientific.

[19] Margrabe, W. (1978) 'The Value of an Option to Exchange One Asset for Another.' Journal of Finance 33, 177-186.

[20] McNeil, A.J., Frey, R. and Embrechts, P. (2005) Quantitative Risk Management. Princeton University Press, United Kingdom.

[21] Merton, R.C. and Perold, A.F. (1993) 'Theory of Risk Capital in Financial Firms.' Journal of Applied Corporate Finance 6, 16-32.

[22] Modigliani, F. and Miller, M.H. (1958) 'The Cost of Capital, Corporation Finance, and the Theory of Investment.' American Economic Review 48, 261-297.

[23] Myers, S.C. and ReAD, J.A. (2001) 'Capital Allocation for Insurance Companies.' Journal of Risk and Insurance 3, 187-221.

[24] Panning, W.H. (2006) 'Managing the Invisible: Measuring Risk, Managing Capital, Maximizing Value.' Willis Re Working Paper.

[25] Phillips, R.D., Cummins, J.D. and Allen, F. (1998) 'Financial Pricing of Insurance in the Multiple Line Insurance Company.' Journal of Risk and Insurance 65, 597-636.

[26] Sherris, M. (2006) 'Solvency, Capital Allocation and Fair Rate of Return in Insurance.' Journal of Risk and Insurance 73, 71-96.

[27] Sherris, M. and van Der Hoek, J. (2006) 'Capital Allocation in Insurance: Economic Capital and the Allocation of the Default Option Value.' North American Actuarial Journal 10, $39-61$.

[28] Smith, J.E. (1996) 'Fisher Separation and Project Valuation in Partially Complete Markets.' Duke University Working Paper.

[29] STulz, R.M. (2003) Risk Management and Derivatives. South-Western, Ohio.

[30] Sutherland-Wong, C. and Sherris, M. (2005) 'Risk-Based Regulatory Capital for General Insurers: A Case Study.' Journal of Actuarial Practice 12, 5-46. 
[31] Swiss Re (2005) 'Insurers' cost of capital and economic value creation: principles and practical implications.' Swiss Re Technical Publishing Sigma No. 3.

[32] TAng, A. and Valdez, E.A. (2004) 'Economic Capital and the Aggregation of Risks Using Copulas.' UNSW Working Paper.

[33] Torczon, V. (1997) 'On the Convergence of Pattern Search Algorithms.' SIAM Journal on Optimization 7, 1-25.

[34] Warner, J.B. (1977) 'Bankruptcy Costs: Some Evidence.' Journal of Finance 32, 337-348.

[35] Yow, S. and Sherris, M. (2007) 'Enterprise Risk Management, Insurer Pricing, and Capital Allocation.' UNSW Actuarial Studies Working Paper and Paper presented to the Bowles Symposium and ERM Symposium, Chicago, March.

[36] Zanjani, G. (2002) 'Pricing and Capital Allocation in Catastrophe Insurance.' Journal of Financial Economics 65, 283-305.

\section{SHAUn Yow}

The Boston Consulting Group

Level 28, Chifley Tower, 2 Chifley Square

Sydney, NSW, Australia, 2000

E-Mail:yow.shaun@bcg.com

\section{Michael SHERRIS}

School of Actuarial Studies, Faculty of Business

University of New South Wales

Sydney, NSW, Australia, 2052

E-Mail:m.sherris@unsw.edu.au 